\title{
Individual Differences in Novelty Seeking Predict Subsequent Vulnerability to Social Defeat through a Differential Epigenetic Regulation of Brain-Derived Neurotrophic Factor Expression
}

\author{
Florian Duclot and Mohamed Kabbaj \\ Department of Biomedical Sciences, Neuroscience Program, Florida State University, Tallahassee, Florida 32306
}

\begin{abstract}
Some personality traits, including novelty seeking, are good predictors of vulnerability to stress-related mood disorders in both humans and rodents. While high-novelty-seeking rats [high responders (HRs)] are vulnerable to the induction of depressive-like symptoms by social defeat stress, low-novelty-seeking rats [low responders (LRs)] are not. Here, we show that such individual differences are critically regulated by hippocampal BDNF. While LR animals exhibited an increase in BDNF levels following social defeat, HR individuals did not. This difference in hippocampal BDNF expression promoted the vulnerability of HR and the resilience of LR rats. Indeed, preventing activation of BDNF signaling by infusing the BDNF scavenger TrkB-Fc into the dentate gyrus of the hippocampus of LR rats led to social defeat-induced social avoidance, whereas its activation in HR rats by the TrkB agonist 7,8-dihydroxyflavone promoted social approach. Along with the changes in BDNF expression following defeat, we report in LR animals a downregulation of the inactive BDNF receptor TrkB.T1, associated with an activation of CREB through Akt-mediated signaling, but not MSK1-mediated signaling. In HR animals, none of these molecules were affected by social defeat. Importantly, the BDNF upregulation involved an epigenetically controlled transcription of $b d n f$ exon VI, associated with a coherent regulation of relevant epigenetic factors. Altogether, our data support the importance of hippocampal BDNF regulation in response to stressful events. Moreover, we identify a specific and adaptive regulation of $b d n f$ exon VI in the hippocampus as a critical regulator of stress resilience, and strengthen the importance of epigenetic factors in mediating stressinduced adaptive and maladaptive responses in different individuals.
\end{abstract}

\section{Introduction}

Depression is a debilitating disorder affecting many aspects of the human personality and is characterized by high individual variability in both the sensitivity to treatment and vulnerability to develop symptoms (Warden et al., 2007). It therefore becomes critical to consider such individual differences in the etiology of depression. Several clinical reports indicate that personality traits, including novelty seeking, can be used to predict further vulnerability to mood disorders (Josefsson et al., 2011; Black et al., 2012; Wu et al., 2012). The social defeat stress is an ethologically relevant model of depression with good face, construct, and predictive validity (Björkqvist, 2001; Nestler and Hyman, 2010), which allows the discrimination of vulnerable and resilient animals (Krishnan et al., 2007). However, only a few animal models

\footnotetext{
Received Jan. 15, 2013; revised May 28, 2013; accepted May 29, 2013.

Author contributions: F.D. and M.K. designed research; F.D. performed research; F.D. and M.K. analyzed data; F.D. and M.K. wrote the paper.

This work was supported by National Institute of Mental Health Grants R01 MH087583, R21 MH081046, and R21 MH083128, as well as the Department of Biomedical Sciences at Florida State University.

The authors declare no financial conflicts of interest.

Correspondence should be addressed to Mohamed Kabbaj, College of Medicine, Florida State University, $1115 \mathrm{~W}$ Call Street, Tallahassee, FL 32306. E-mail: mohamed.kabbaj@med.fsu.edu.

DOI:10.1523/JNEUROSCI.0199-13.2013

Copyright $\odot 2013$ the authors $\quad 0270-6474 / 13 / 3311048-13 \$ 15.00 / 0$
}

have been developed for studying basal variability in personality traits as predictors of vulnerability to depression.

In response to the mild stress of a novel environment, rats exhibit either high rates [high responders (HRs)] or low rates [low responders (LR)] of exploratory locomotion (Piazza et al., 1989). We recently established that HR animals exhibited a higher vulnerability to social defeat-induced anhedonia, reduction in body weight gain, contextual fear, and social avoidance, compared with LR rats (Duclot et al., 2011), together with an impaired neuroendocrine response (Calvo et al., 2011). Although a differential regulation of histone acetylation was detected in the hippocampus (Hollis et al., 2011), the molecular mechanisms linking novelty seeking and higher vulnerability to social defeat remain unclear.

In rodents, chronic social stress downregulates brain-derived neurotrophic factor (BDNF) transcription in the hippocampus (Haenisch et al., 2009; Komatsu et al., 2011) through an increase in repressive histone methylation (Tsankova et al., 2006). Moreover, classic antidepressants increase hippocampal BDNF levels (Nibuya et al., 1995), which exerts antidepressant effects (Shirayama et al., 2002; Hoshaw et al., 2005). Antidepressants can also reverse the $b d n f$ downregulation induced by social defeat through enhancement of histone acetylation at $b d n f$ promoters (Tsankova et al., 2006)_an observation supported 
by the reported antidepressant effects of histone deacetylase inhibitors (Schroeder et al., 2010). Importantly, BDNF regulation after stress has been suggested as an important mediator of vulnerability and resilience. While higher BDNF levels in the nucleus accumbens (NAcc) promote vulnerability to social defeat in mice (Krishnan et al., 2007), higher BDNF levels in the hippocampus promote resilience to a chronic mild stress (CMS; Bergström et al., 2008; Taliaz et al., 2011). Furthermore, disruption in long-term BDNF adaptations in the hippocampus is associated with social defeat-induced vulnerability to subsequent stress (Blugeot et al., 2011). Together, these data establish BDNF as a critical regulator of stress resilience, but its exact role in vulnerability to social defeat and the underlying mechanisms remain unknown.

We therefore investigated whether differences in BDNF response mediated the individual differences in vulnerability to social defeat by analyzing the regulation of $b d n f$ and its specific transcripts in the hippocampus of LR and HR animals following social defeat. After testing whether a hippocampal modulation of BDNF signaling would control vulnerability or resilience, we uncovered coordinated but local epigenetic correlates.

\section{Materials and Methods}

Animals. Eight-week-old male Sprague Dawley rats weighing 250$275 \mathrm{~g}$ (Charles River Laboratories), randomly pair-housed, were used in this study. As the measurement of locomotor activity in response to novelty was performed $5 \mathrm{~d}$ after reception at the vivarium, and to avoid any additional social stress due to further modification of cagemates, the distribution of HR/LR phenotypes among cages was random, and both animals of one pair received the same treatment, i.e., defeated or not. Additionally, vasectomized male Long-Evans rats weighing 325-350 g were pair-housed with a normal cycling female to enhance territorial behavior and aggressiveness. These Long-Evans males served as the resident attackers during the social defeat procedure and were chosen for consistent aggressive behavior. Before each social defeat session, the resident's mate was transferred to another cage. Rats were maintained on a $12 \mathrm{~h}$ light/dark cycle (lights off at 7:00 P.M.) with food and water available ad libitum except during testing. All experiments were performed during the first $5 \mathrm{~h}$ of the light phase of the light/dark cycle, in accordance with the guidelines of the Animal Care and Use Committee of Florida State University and National Institutes of Health guidelines.

Locomotor activity and determination of HR/LR phenotype. After $5 \mathrm{~d}$ of habituation to the vivarium and handling, the locomotor response to a novel environment was measured using circular activity chambers (Med Associates Inc.), and was used for the classification into HR and LR groups as previously described (Duclot et al., 2011).

Social defeat procedure. The social defeat stress was performed as previously described (Duclot et al., 2011). Briefly, Sprague Dawley males (intruders) were exposed to one [acute (A)] or four [repeated (R)] defeat sessions in the home cage of an aggressive Long-Evans male rat (resident), consisting of 5 min of physical contact, followed by $10 \mathrm{~min}$ of full sensorial interaction while protected in a wire-mesh cage. Nondefeated control animals $(\mathrm{N})$ were placed for $15 \mathrm{~min}$ in a soiled, empty cage of an unfamiliar Long-Evans rat. To avoid any potential effects between defeated animals and nondefeated cagemates, individuals in the same cage received the same treatments.

Social approach and avoidance test. One week after the last defeat session, the social avoidance (Berton et al., 2006) was measured as described previously (Duclot et al., 2011). Briefly, the test consisted of three consecutive 5 min sessions, where the animal was placed in a squared openfield arena first empty, then containing an empty wire mesh cage ("no target"), and finally containing a caged unfamiliar Long-Evans rat ("target"). The time spent in an interaction zone delineated around the cage, as well as the mean distance to the cage, was measured using an automated video tracking system (Ethovision XT 8.0, Noldus Information Technology).
Cannula implantation. Animals were anesthetized with a ketamine (70 $\mathrm{mg} / \mathrm{kg}) / x y l a z i n e(10 \mathrm{mg} / \mathrm{kg}) \mathrm{mix}$, placed in a stereotaxic apparatus, and bilaterally implanted with stainless steel guide cannulae aimed to the dentate gyrus (DG) using the following previously described coordinates (Carrier and Kabbaj, 2012): $-4.3 \mathrm{~mm}$ anteroposterior, $\pm 3.0 \mathrm{~mm}$ lateral, and $-3.7 \mathrm{~mm}$ dorsoventral, relative to bregma (Paxinos and Watson, 1998). At the end of the surgery, stainless steel stylets were placed in the guide cannulae, protruding $1 \mathrm{~mm}$ below the end of the cannulae. To avoid clogging of the cannulae, the stylets were replaced daily over the course of 2 weeks, thereby habituating animals to the procedure and limiting stress induced by the manipulations.

Drug infusions. The recombinant TrkB-Fc chimera (R\&D Systems) was dissolved in PBS, pH 7.4, as stock, and diluted to a final concentration of $0.5 \mu \mathrm{g} / \mu \mathrm{l}$ in a mixture of PBS and artificial CSF (aCSF; $1: 1 \mathrm{v} / \mathrm{v}$ ) containing $0.1 \%$ BSA, as previously described (Wang et al., 2007). The same mixture of PBS/aCSF containing $0.1 \%$ BSA was used as a vehicle control for TrkB-Fc. The selective TrkB agonist 7,8-dihydroxyflavone (7,8-DHF; TCI America) was dissolved in 17\% DMSO-PBS as stock, and further diluted with aCSF to a final concentration of $10 \mu \mathrm{m}$ immediately before each infusion ( $0.02 \%$ final DMSO), as previously described (Zeng et al., 2011). aCSF containing $0.02 \%$ DMSO was used as a vehicle control for 7,8-DHF. Injections were made with a 27 -gauge needle that extended $1 \mathrm{~mm}$ below the guide cannula into the target area, in an injection volume of $2 \mu \mathrm{l}$ per side over $2 \mathrm{~min}$. The injectors were left in place for 2 additional minutes after the end of the injection to ensure optimum diffusion and minimize the distribution of the compound upward on the cannula tract. The TrkB-Fc chimera protein and 7,8-DHF were injected $30 \mathrm{~min}$ and $2 \mathrm{~h}$ before the beginning of each defeat session, respectively. All doses and times of injection were chosen based on previous in vivo and in vitro studies (Wang et al., 2007; Jang et al., 2010; Mizoguchi et al., 2011; Zeng et al., 2011; Devi and Ohno, 2012). At the end of the experiment, placement of all cannulae was verified, and subjects with misplaced cannulae were excluded from data analysis.

RNA and protein levels analysis. Two hours and $30 \mathrm{~min}$ or $6 \mathrm{~h}$ after the last defeat session, animals were killed by decapitation, the brain was removed, and the dorsal hippocampi were tissue punched. Total RNA and proteins were extracted using the TRI-Reagent protocol according to the manufacturer's instructions (Molecular Research Center). A quantity of $0.5 \mu \mathrm{g}$ of total RNA was processed for complementary DNA synthesis and then was analyzed by semi-quantitative real-time PCR (qRT-PCR) as previously described (Hollis et al., 2011), with normalization to the nicotinamide adenine dinucleotide dehydrogenase gene. All reactions were performed in triplicate, and their specificity was verified by melting curve analysis and subsequent separation on a $2 \%$ agarose gel. All primer sequences used in this study are listed in Table 1.

Following separation on $12 \%$ SDS polyacrylamide gels, proteins were transferred to nitrocellulose membranes and incubated with the following primary antibodies targeting: p-AKT (ser473), Akt, p-MSK1 (ser376), CREB, pTrkB (Tyr516), total-TrkB, p-ERK1/2, and totalERK1/2 (purchased from Cell Signaling Technology); MSK1 (purchased from Santa Cruz Biotechnology); and p-CREB (ser133; purchased from Millipore). After incubation with goat anti-rabbit IR Dye 680LT or goat anti-mouse IR Dye 800CW fluorescent secondary antibodies, the membranes were visualized using an Odyssey infrared imaging system (LICOR Biosciences). The specific signal was quantified using NIH ImageJ software (http://rsb.info.nih.gov/ij/) and normalized within the same membrane to the relative nonphosphorylated form of the protein.

BDNF contents measured by ELISA. Two hours and $30 \mathrm{~min}$ or $6 \mathrm{~h}$ after the last defeat encounter, animals were killed by decapitation; the brains were quickly removed and snap frozen; and the dorsal hippocampi were tissue punched. All punches from both hemispheres were separated equally into two different tubes, while mixing both hemispheres, and stored at $-80^{\circ} \mathrm{C}$ until being processed. One tube was therefore used for RNA extraction (see above), and the other tube for the measurement of BDNF contents. BDNF protein contents were measured using a conventional two-site ELISA (BDNF Emax immunoassay, Promega), following the manufacturer's recommendations for the measurement of free mature BDNF, and with minor modifications as previously described (Givalois et al., 2004). The assay sensitivity was $15 \mathrm{pg} /$ well, and the cross- 
Table 1. List of all primers used in this study, with sequence, respective GenBank accession number, amplicon length, and reference

\begin{tabular}{|c|c|c|c|c|}
\hline & GenBank accession number & Primer sequence $\left(5^{\prime}-3^{\prime}\right)$ & Amplicon length & Reference \\
\hline \multicolumn{5}{|l|}{ mRNA } \\
\hline pan-BDNF & NM_001270638 & $\begin{array}{l}\text { CCATAAGGACGCGGACTTGTAC } \\
\text { AGACATGTTTGCGGATCCAGG }\end{array}$ & 121 & Tsankova et al., 2004 \\
\hline BDNF_exl & EF125675 & $\begin{array}{l}\text { CAGGACAGCAAAGCCACAAT } \\
\text { GCCTTCATGCAACCGAAGTA }\end{array}$ & 95 & Wei et al., 2010 \\
\hline BDNF_exIV & EF125679 & $\begin{array}{l}\text { GCTGCCTTGATGTTTACTTTGA } \\
\text { CGTGGACGTTTGCTTCTTTC }\end{array}$ & 144 & Wei et al., 2010 \\
\hline BDNF_exVI & EF125680 & $\begin{array}{l}\text { GATCCGAGAGCTTTGTGTGG } \\
\text { CGTGGACGTTTGCTTCTTTC }\end{array}$ & 131 & Wei et al., 2010 \\
\hline BDNF_exIXa & EF125690 & $\begin{array}{l}\text { GTCTCTGCTTCCTTCCCACA } \\
\text { CGTGGACGTTTGCTTCTTTC }\end{array}$ & 124 & Wei et al., 2010 \\
\hline TrkB.FL & M55291 & $\begin{array}{l}\text { TATGCTGTGGTGGTGATTGC } \\
\text { TTGGAGATGTGGTGGAGAGG }\end{array}$ & 158 & Wei et al., 2010 \\
\hline TrkB.T1 & M55292 & $\begin{array}{l}\text { GGCAACAGTAGTCCCAGGAG } \\
\text { AGTTGGCGAGACATTCCAAG }\end{array}$ & 155 & Wei et al., 2010 \\
\hline KAT2B (PCAF) & XM_003750617 & $\begin{array}{l}\text { GCTTTACAGCACGCTCAAGA } \\
\text { GTTCCATGAAGGGCCAAG }\end{array}$ & 71 & Bousiges et al., 2010 \\
\hline KAT5 (Tip60) & NM_001005872 & $\begin{array}{l}\text { ACAATGTGGCCTGCATCTT } \\
\text { CTTCTACTTTCGAGAGTTCATAGCTG }\end{array}$ & 96 & Bousiges et al., 2010 \\
\hline CREBBP (CBP) & NM_133381 & $\begin{array}{l}\text { GACCAAGATGGGGATGACTG } \\
\text { CCACTGATGTTTGCAACTGG }\end{array}$ & 206 & Hollis et al., 2011 \\
\hline Mll1 & XM_003750506 & $\begin{array}{l}\text { CACCCCTGCGGTCCAAGCTC } \\
\text { GCGCGATCCGTTGCTTTGGC }\end{array}$ & 136 & Own design \\
\hline $\mathrm{Kdm} 3 \mathrm{a}$ & NM_175764 & $\begin{array}{l}\text { CGTGGCACAGCTGCCCAAGT } \\
\text { GGCAGCCACAAGCCAATCGC }\end{array}$ & 198 & Own design \\
\hline NADH & EU10471 & $\begin{array}{l}\text { CTATTAATCCCCGCCTGACC } \\
\text { GGAGCTCGATTTGTTTCTGC }\end{array}$ & 71 & Own design \\
\hline Genomic DNA & & & & \\
\hline BDNF_P6 & NW_047673 & $\begin{array}{l}\text { TGCAGGGGAATTAGGGATAC } \\
\text { TCTTCGGTTGAGCTTCGATT }\end{array}$ & 166 & Tsankova et al., 2004 \\
\hline BSP & & & & \\
\hline BDNF_P6 & NW_047673 & $\begin{array}{l}\text { TAGGTATAGAGTTTTGGGGTTAA } \\
\text { AACACCCAAAACTCAACC }\end{array}$ & 273 & Own design \\
\hline
\end{tabular}

BSP, Bisulfite-PCR.

reactivity with other related neurotrophic factors was $<3 \%$. The intraassay and interassay coefficients of variation were $3 \%$ and $6 \%$, respectively. To confirm the specific measurement of the mature form of the protein, proteins extracted from the same animals (the other half of the dorsal hippocampus) were analyzed by Western blot using an antibody detecting both the pro-BDNF and mature BDNF (Santa Cruz Biotechnology).

Chromatin immunoprecipitation. After cross-linking with $1 \%$ formaldehyde, chromatin was sheared using a Branson digital sonifier 250 to fragments of 200-500 bp. Immunoprecipitation was realized overnight at $4^{\circ} \mathrm{C}$ with an antibody directed against histone $\mathrm{H} 3$ dimethylated on the lysine residue 4 ( $\mathrm{H} 3 \mathrm{~K} 4 \mathrm{me}^{2}$; Abcam), histone $\mathrm{H} 3$ acetylated on the lysine residues 9 and 14 (AcK9K14H3) or dimethylated on the lysine residue 9 ( $\mathrm{H} 3 \mathrm{~K} 9 \mathrm{me}^{2}$; Millipore). After washes, elution from beads, and reversal of the cross-link, immunoprecipitated DNA was purified and analyzed in triplicate by qRT-PCR with an internal standard curve prepared from pooled input samples. The primers used in this study are listed in Table 1. Specific enrichment versus DNA immunoprecipitated with normal rabbit IgG (Millipore) was verified for each antibody. Each sample was normalized with the respective input value, and data were expressed as a percentage of LR-N animals.

Measurement of DNA methylation. Following genomic DNA extraction from dorsal hippocampus punches, the methylation status at the $b d n f$ promoter 6 was measured via direct bisulfite DNA sequencing PCR, as previously described (Zhao et al., 2005; Niculescu et al., 2006; Roth et al., 2011). Following bisulfite conversion using an Epitect bisulfite kit (Qiagen), DNA was amplified by primers designed using the Methyl Primer Express software (Applied Biosystems), targeting a CpG-rich region within the $b d n f$ promoter 6 that included the transcription start site (NW_047673.1; see Table 1 for primers sequences). PCR products were then separated on an agarose gel, purified using a gel extraction kit (Sigma-Aldrich), and sequenced using the reverse primer at the Florida State University DNA sequencing facility of the Department of Biological Sciences. Sequencing traces were then analyzed as previously described (Jiang et al., 2010a). Briefly, the percentage of methylation of each $\mathrm{CpG}$ site was calculated from the ratio between the peak values of $\mathrm{C}$ and $\mathrm{T}(\mathrm{C} /[\mathrm{C}+\mathrm{T}])$, determined using the Chromas software. Complete bisulfite conversion of unmethylated cytosine was verified on the chromatograms as all cytosine from non$\mathrm{CpG}$ sites were converted to thymidine. Moreover, to confirm the accuracy and sensitivity of the procedure, rat methylated standards (EpigenDx) were processed in parallel and analyzed as described above. The standard curve thus generated confirmed a proportional increase of the calculated methylation percentage with the expected methylation rate $\left(R^{2}=0.995\right.$, slope $\left.=1.070\right)$.

Statistical analyses. The mean distance to the cage and time spent in the interaction zone during the social approach and avoidance test were analyzed within the same phenotype (HR or LR, separately) using a two-way ANOVA for repeated measures with "drug" [vehicle (Veh)-Fc/ TrkB-Fc in LR, and Veh-DHF/7,8-DHF in HR] as the independent factor, and "session" (no target/target) as the within-groups factor. All other data were analyzed using a two-way ANOVA with HR/LR, and social defeat (or time) as the independent factor. All ANOVAs were followed, when appropriate, by a Student-Newman-Keuls and Scheffe's post hoc tests correcting for multiple comparisons, with a significance threshold of $p<0.05$. In all cases, both post hoc tests yielded the same conclusion (significant or not significant), but only the Scheffé's $p$ value is reported throughout the article. Additionally, rats' locomotion in the first session of the social approach and avoidance test was analyzed with unpaired two-tailed $t$ tests. All statistical analyses were performed using the StatView software (SAS Institute). 


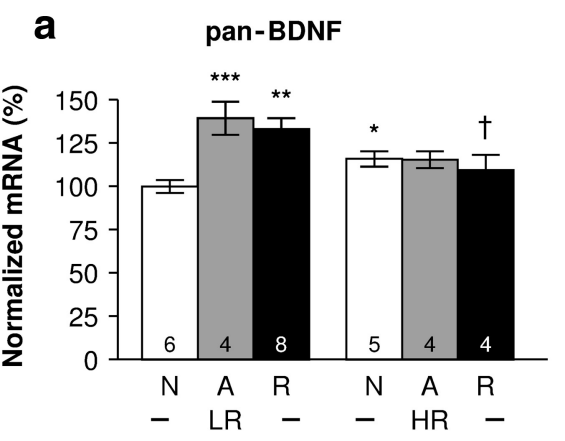

b

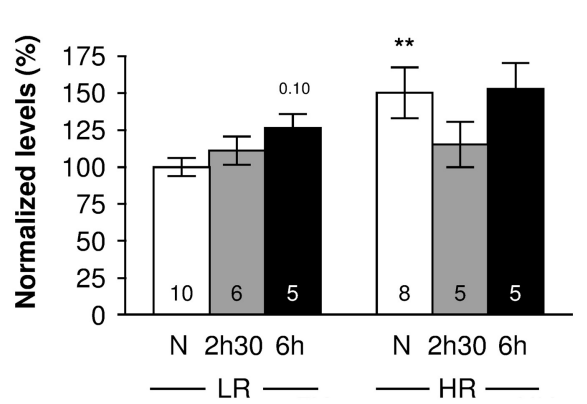

Figure 1. HR and LR animals exhibit individual differences in BDNF mRNA and protein levels in the hippocampus at baseline and in response to social defeat. $a, H R$ and $L R$ animals were exposed to one $(A)$ or four social defeat sessions $(R)$, or to an empty cage of a Long-Evans rat (N), and were killed $2 \mathrm{~h}$ and $30 \mathrm{~min}$ later for analysis of BDNF $m$ RNA by real-time PCR. $\boldsymbol{b}, \mathrm{HR}$ and $\mathrm{LR}$ animals were exposed to an empty Long-Evans rat cage (N) or to four defeat sessions and were killed $2 \mathrm{~h}$ and $30 \mathrm{~min}(2 \mathrm{~h} 30)$ or $6 \mathrm{~h}$ after the end of the last defeat session. Half of the dorsal hippocampus was used for measuring BDNF protein contents by ELISA ( $\boldsymbol{b}$ ). The number of animals per group $(n=4-10)$ is shown within columns, and data are presented as the mean \pm SEM. Data were analyzed with a two-way ANOVA with HR/LR and defeat, or time in $\boldsymbol{b}$, as independent factors, followed by Scheffé's post hoc test where appropriate. ${ }^{*} p<0.05,{ }^{* *} p<0.01$, and ${ }^{* * *} p<0.001$ versus $L R-N,+p<0.05$ versus $L R-R$, Scheffé's post hoc test.

\section{Results}

\section{Social defeat induces an increase in BDNF levels in the} hippocampus of LR but not HR animals

Previously, we showed that high-novelty-seeking animals (HRs) have a higher vulnerability to four to six sessions of social defeat, compared with low-novelty-seeking animals (LRs; Calvo et al., 2011; Duclot et al., 2011). To elucidate the underlying molecular events, LR and HR animals underwent one (A) or four (R) defeat sessions, and the pan-BDNF mRNA and protein levels were measured $2 \mathrm{~h}$ and 30 min later in the hippocampus.

At baseline, nondefeated HR animals had higher pan-BDNF mRNA levels than their LR counterparts $(+16 \%, p=0.022)$. Interestingly, LR animals showed an increase in response to both acute and repeated defeat $(\mathrm{A}:+39 \%, p=0.005$; $\mathrm{R}:+33 \%, p=$ 0.005 ), whereas HR individuals did not (two-way ANOVA: $F_{(1,25)}=3.84, p=0.061$ for HR/LR; $F_{(2,25)}=4.63, p=0.019$ for defeat; and $F_{(2,25)}=6.55, p=0.005$ for the interaction; Fig. 1a). Furthermore, although higher than in LR animals at baseline, hippocampal BDNF protein contents remained unaffected by the repeated defeat procedure in HR animals (two-way ANOVA: $F_{(1,33)}=6.15, p=0.018$ for HR/LR; $F_{(2,33)}=1.70, p=0.198$ for defeat; and $F_{(2,33)}=1.68, p=0.201$ for the interaction; Fig. $\left.1 b\right)$. In LR animals, however, we observed a trend for increased BDNF protein levels following repeated social stress $6 \mathrm{~h}$ following the last defeat exposure $(p=0.105)$.

\section{Individual differences in BDNF response mediate the vulnerability to social defeat}

In the previous experiments, we showed that LR animals, but not HR animals, exhibited an increase in both BDNF mRNA and protein levels (although significant only for mRNA levels). Since antidepressants seem to have their beneficial effects through an increase in hippocampal BDNF contents (Nibuya et al., 1995; Shirayama et al., 2002; Yan et al., 2010), we hypothesized that the BDNF upregulation observed in LR animals following repeated social defeat is adaptive and mediates their behavioral resilience. HR rats, lacking such protective upregulation of BDNF, would thus be vulnerable to repeated social defeat. We therefore asked whether preventing BDNF signaling in LR animals would promote, while activating BDNF signaling in HR animals would reverse vulnerability to a repeated social defeat procedure. Importantly, the DG subregion of the hippocampus plays a major role for BDNF-mediated stress resilience and antidepressant response (Adachi et al., 2008; Taliaz et al., 2010; Taliaz et al., 2011). To prevent BDNF signaling, TrkB-Fc was infused into the DG of LR animals before each defeat session. TrkB-FC is a fusion protein acting as a BDNF scavenger. Conversely, HR rats were infused with the selective TrkB agonist 7,8-DHF (Jang et al., 2010; Liu et al., 2010) into the DG before each defeat session. Then, vulnerability to the effects of the repeated defeat procedure was assessed 1 week after the last defeat session using the social approach and avoidance test (Fig. 2a).

None of the treatments affected rats' locomotion in the test arena $(3687 \pm 316$ $\mathrm{cm}$ for LR-Veh; $3865 \pm 374 \mathrm{~cm}$ for LR-Fc; unpaired $t$ test: $t_{(9)}=0.37, p=0.722 ; 3928 \pm 270 \mathrm{~cm}$ for HR-Veh, and $4688 \pm 468 \mathrm{~cm}$ for HR-DHF, $\left.t_{(11)}=1.46, p=0.172\right)$. In LR rats, although no main effect of the session (no target or target) was observed, animals treated with TrkB-Fc before each social defeat exposure stayed further away from the social target (cage containing an unfamiliar Long-Evans, target session) than VehFc-treated rats (two-way repeated-measures ANOVA: $F_{(1,9)}=$ $7.86, p=0.021$ for drug; $F_{(1,9)}=1.95, p=0.196$ for session; and $F_{(1,9)}=7.40, p=0.024$ for the interaction; Fig. $\left.2 c\right)$. Although it did not reach significance, we observed a similar trend when measuring the time spent in the interaction zone, with TrkB-Fctreated LR rats tending to spend less time in the interaction zone than Veh-Fc-treated LR animals (two-way repeated-measures ANOVA: $F_{(1,9)}=4.81, p=0.056$ for drug; $F_{(1,9)}=1.96, p=0.195$ for session; and $F_{(1,9)}=2.68, p=0.136$ for the interaction; Fig. 2d). In HR rats, treatment with 7,8-DHF before each social defeat session significantly improved the social approach behavior compared with Veh-DHF-treated animals, measured by a reduced distance to the cage (Fig. 2e) and more time spent in the interaction zone (Fig. 2f) during the target session (two-way repeatedmeasures ANOVA: mean distance to the cage: $F_{(1,11)}=2.42$, $p=0.148$ for drug; $F_{(1,11)}<1$ for session; and $F_{(1,11)}=7.36, p=$ 0.020 for the interaction; time in interaction zone: $F_{(1,11)}=5.55$, $p=0.038$ for drug; $F_{(1,11)}<1$ for session; and $F_{(1,11)}=6.24, p=$ 0.029 for the interaction). These data demonstrate that preventing the activation of BDNF signaling in the DG of LR animals promotes vulnerability to social defeat, whereas its activation in the DG of HR animals promotes resilience. This observation therefore indicates that the BDNF upregulation observed in the hippocampus of LR animals mediated their resilience to a repeated exposure to social defeat.

\section{Social defeat activates TrkB-Akt-CREB signaling pathway in LR rats, but not in HR rats}

In the hippocampus, most antidepressant treatments increase BDNF expression, which also exerts potent antidepressant effects by itself (Duman and Monteggia, 2006). Moreover, the activation of BDNF downstream targets upon binding to its receptors is required for its therapeutic effects (Saarelainen et al., 2003). We therefore asked whether the BDNF upregulation observed in LR animals following social defeat would activate BDNF down- 
a

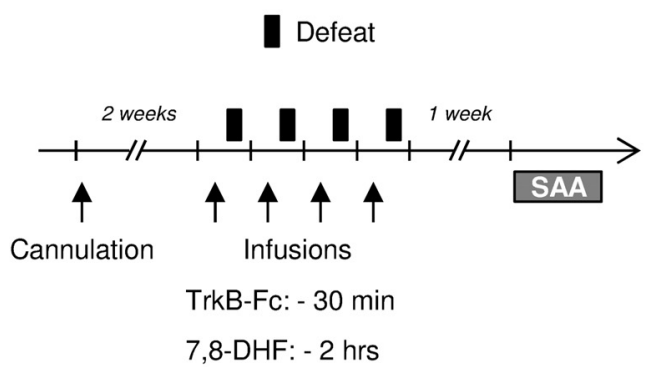

b

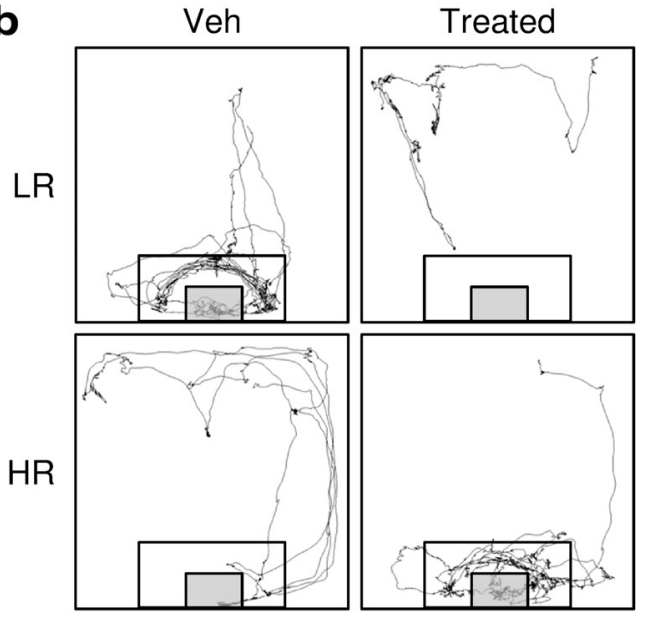

C
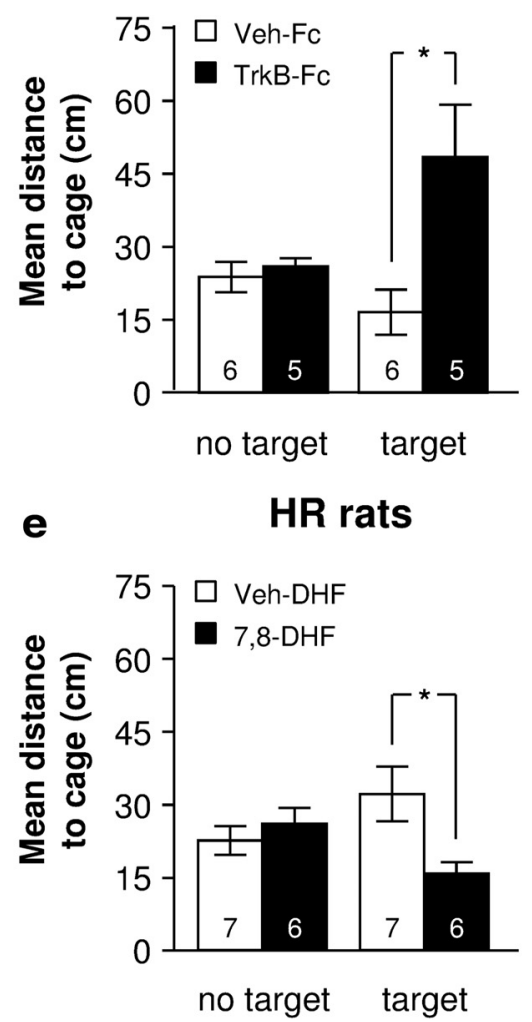

d LR rats

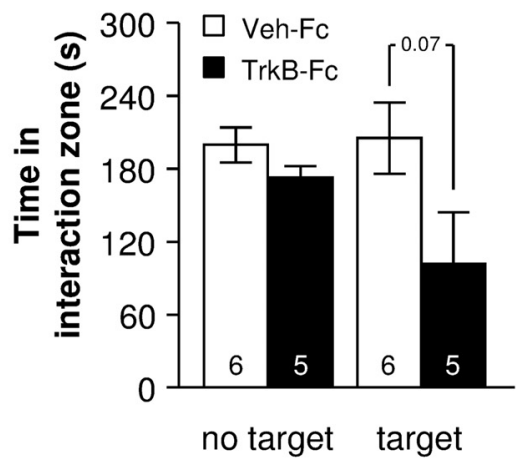

HR rats

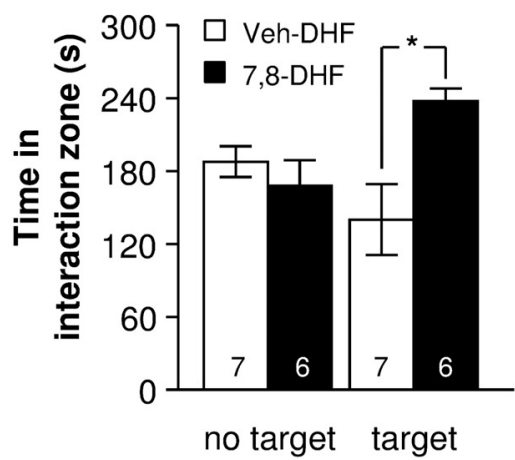

Figure 2. Individual differences in BDNF regulation in response to social defeat mediate the vulnerability to the development of depressive-like symptoms. The extracellular BDNF scavenger TrkB-Fc, or the selective TrkB agonist 7,8-DHF, was infused into the dentate gyrus of LR or HR animals, respectively, before each defeat session of a repeated social defeat paradigm. Their respective vulnerability to the defeat procedure was assessed 1 week after the last defeat encounter by using the social approach and avoidance test (SAA). $\boldsymbol{a}$, Experimental timeline. $\boldsymbol{b}$, Representative tracks acquired by the video tracking system when a wire-mesh cage (gray box) containing an unfamiliar Long-Evans rat (target session) was introduced in the arena. The inner rectangle represents the interaction zone. $\boldsymbol{c}-\boldsymbol{f}$, Mean distance in centimeters to the cage $(\boldsymbol{c}, \boldsymbol{e})$ and total time spent in the interaction zone $(\boldsymbol{d}, \boldsymbol{f})$ during the no target and target sessions for $L R(\boldsymbol{c}, \boldsymbol{d})$ and $H R$ rats $(\boldsymbol{e}, \boldsymbol{f})$. The number of animals per group $(n=5-7)$ is shown within columns, and data are presented as the mean \pm SEM. Data were analyzed with a repeated-measures two-way ANOVA with HR/LR as the independent factor, and session (no target or target) as the within-groups factor. ${ }^{*} p<0.05,{ }^{* *} p<0.01$, Scheffé's post hoc test. Fc, TrkB-Fc chimera protein; DHF, 7,8-DHF; Veh-Fc, vehicle for TrkB-Fc; Veh-DHF, vehicle for 7,8-DHF.

stream signaling. Binding of BDNF to the full-length isoform of its high-affinity receptor TrkB (TrkB.FL) triggers internal autophosphorylation events, leading to the phosphorylation of the transcription factor CREB, which in turn promotes neuronal survival and plasticity (Cunha et al., 2010). Several intracellular cascades are activated, including PI3K-Akt, or MAPK with activation of MSK1 (Arthur et al., 2004). BDNF can also bind a truncated, inactive, TrkB splice variant (TrkB.T1) that can act as dominant-negative inhibitor of BDNF signaling by forming heterodimers with the active TrkB.FL isoform (Haapasalo et al., 2002).

TrkB.FL mRNA levels showed a similar profile of regulation in both LR and HR animals with only a trend to an increase $2 \mathrm{~h}$ and $30 \mathrm{~min}$ following acute defeat $\left(F_{(1,35)}<1\right.$ for HR/LR; $F_{(2,35)}=$ $4.76, p=0.015$ for defeat; and $F_{(2,35)}<1$ for the interaction; Fig. $3 a)$. However, HR and LR animals presented with a differential regulation of TrkB.T1 following social defeat, but not at baseline $\left(F_{(1,37)}=2.03, p=0.163\right.$ for HR/LR; $F_{(2,37)}=1.67, p=0.201$ for defeat; and $F_{(2,37)}=3.38, p=0.045$ for the interaction; Fig. $\left.3 a\right)$. Indeed, LR rats exhibited a reduction in TrkB.T1 mRNA levels following defeat (significant only in the repeated paradigm), whereas HR rats did not. Interestingly, when comparing the ratio of the active over the inactive TrkB isoform (FL/T1), acute defeat increased it in both LR and HR rats (Fig. $3 a$ ). Following repeated defeat, however, only LR rats showed a trend to a higher FL/T1 ratio compared with both nondefeated LR rats and repeatedly defeated HR rats $\left(F_{(1,32)}=3.08, p=0.089\right.$ for HR/LR; $F_{(2,32)}=$ $10.7, p=0.0003$ for defeat; and $F_{(2,32)}=1.53, p=0.232$ for the interaction; Fig. $3 a$ ). These data suggest that in addition to enhancing BDNF expression, social defeat reduces the dominantnegative regulation produced by TrkB.T1 in LR rats, thereby promoting greater TrkB.FL availability and increased BDNF signaling.

Accordingly, we observed a significant increase in TrkB phosphorylation in LR animals $6 \mathrm{~h}$ following repeated defeat, when both $b d n f$ exon VI mRNA and BDNF protein levels were increased in LR animals. In HR rats, although higher than LR animals at baseline, TrkB phosphorylation remained unaffected by the social defeat exposure $\left(F_{(1,19)}<1\right.$ for strain; $F_{(1,19)}=4.34, p=$ 0.0509 for defeat; and $F_{(1,19)}=7.86, p=0.0113$ for the interaction; Fig. $3 c$ ). Moreover, TrkB phosphorylation levels following repeated defeat were negatively correlated to the locomotor response of the animals in a novel environment $(r=-0.619, p=$ $\left.0.0317, R^{2}=0.384\right)$, used to determine the HR/LR phenotype, and predicts subsequent vulnerability to social defeat (Duclot et al., 2011).

Although no individual differences were detected at baseline, we observed a significant phosphorylation of Akt following repeated defeat in LR rats only $\left(F_{(1,33)}=8.33, p=0.007\right.$ for HR/LR; $F_{(2,33)}=1.74, p=0.191$ for defeat; and $F_{(2,33)}=2.43, p=0.103$ 


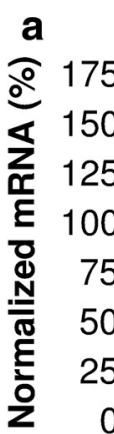

TrkB.FL
TrkB.T1
TrkB.FL / TrkB.T1

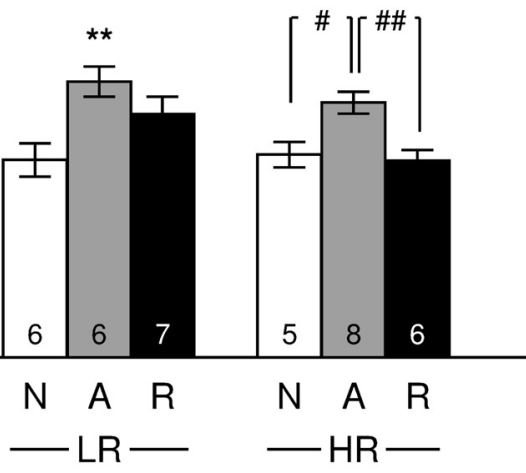

PCREB / CREB

\section{b}

pAkt / Akt

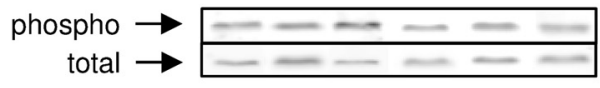

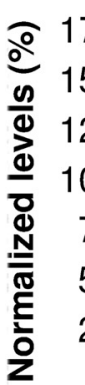
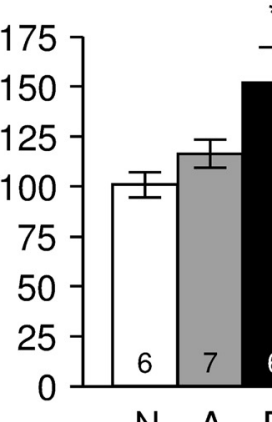

\section{$\dot{1}$}

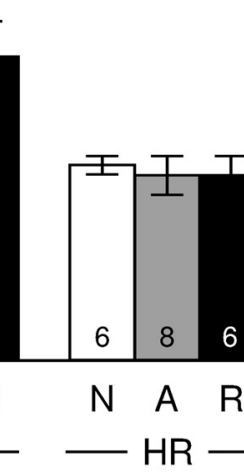

pTrkB / TrkB

C
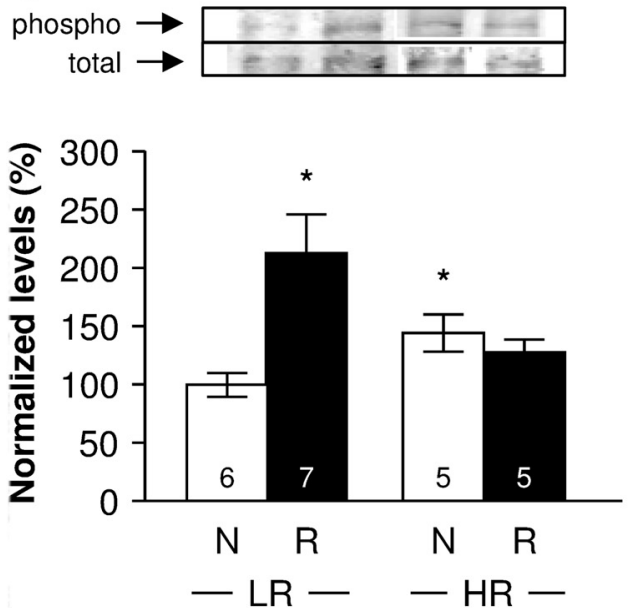
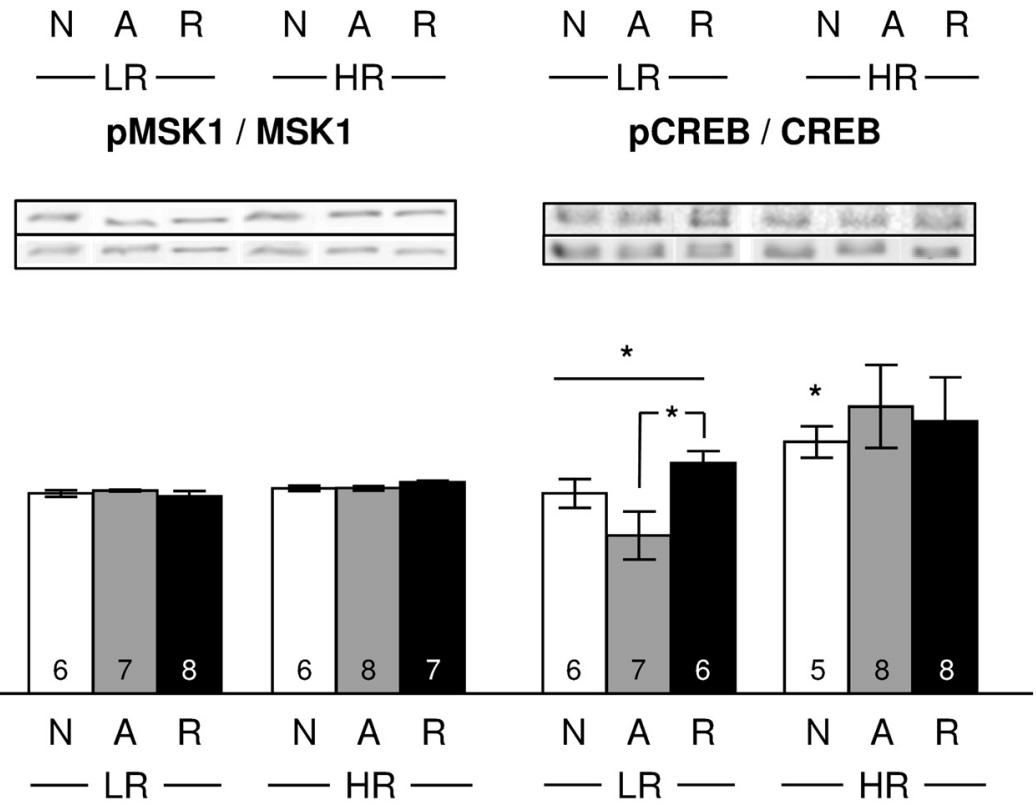

pERK1 / ERK1

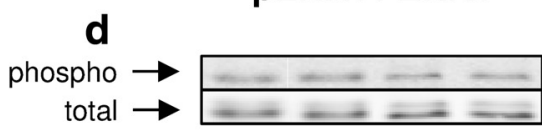

pERK2 / ERK2

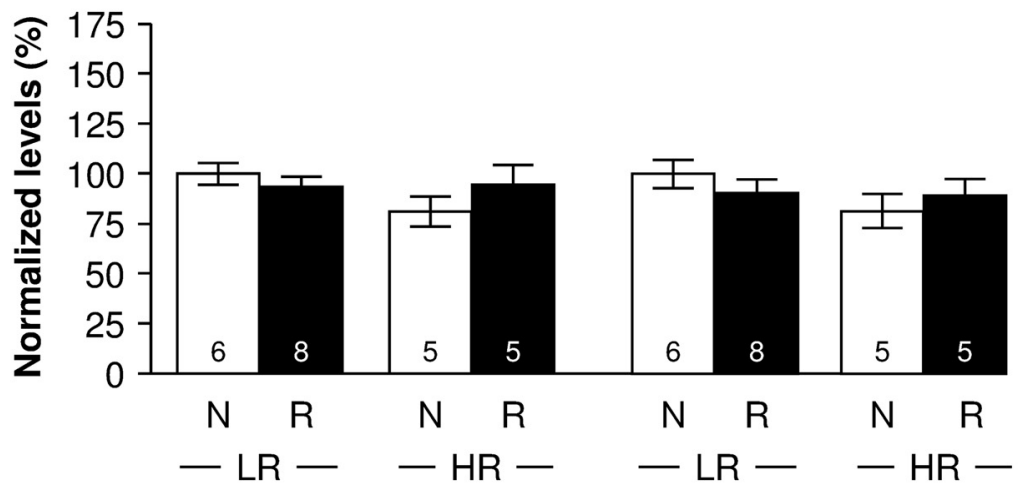

Figure 3. HR and LR animals exhibit individual differences in components of the BDNF signaling pathway. $\boldsymbol{a}$, $H R$ and $L R$ animals were exposed to one ( $A$ ) or four social defeat sessions ( $R$ ), or to an empty cage of a Long-Evans rat (N), and were killed $2 \mathrm{~h}$ and 30 min later for analysis of the BDNF receptor TrkB.FL and TrkB.T1 isoforms mRNA in the hippocampus by real-time PCR. $\boldsymbol{b}-\boldsymbol{d}$, In parallel, the phosphorylation TrkB and its downstream targets Akt, MSK1, ERK1, ERK2, and CREB were analyzed by Western blots $2 \mathrm{~h}$ and $30 \mathrm{~min}(\boldsymbol{b})$ or $6 \mathrm{~h}$ ( $\boldsymbol{c}$, $\boldsymbol{d}$ ) following the last defeat encounter. One typical blot of each condition is shown above the figure in $\boldsymbol{b}-\boldsymbol{d}$, in the same order as the legend. The number of animals per group ( $n=5-9)$ is shown within columns and data are presented as mean \pm SEM. Data were analyzed with a two-way ANOVA with HR/LR and defeat as independent factors, followed by Scheffé's post hoc test where appropriate. ${ }^{*} p<0.05,{ }^{* *} p<0.01$ versus LR-N; " $p<0.05$, \#\# $p<0.001$ versus HR-N; Scheffé's post hoc test.

for the interaction; Fig. 3b). No individual differences and no stress effects were detected for the phosphorylation of MSK1, suggesting that the MAPK pathway might not be involved $\left(F_{(1,36)}=6.78, p=0.013\right.$ for HR/LR; $F_{(2,36)}<1$ for defeat; and
$F_{(2,36)}=2.33, p=0.112$ for the interaction; Fig. $\left.3 b\right)$. In support, ERK1 and ERK2 phosphorylation was not affected in LR animals $2 \mathrm{~h}$ and $30 \mathrm{~min}$ following repeated defeat [phosphorylated ERK1 (pERK1)/ERK1: LR-N, $100 \pm 6.83 \%$; LR-R, $86.9 \pm 8.02 \%$; un- 


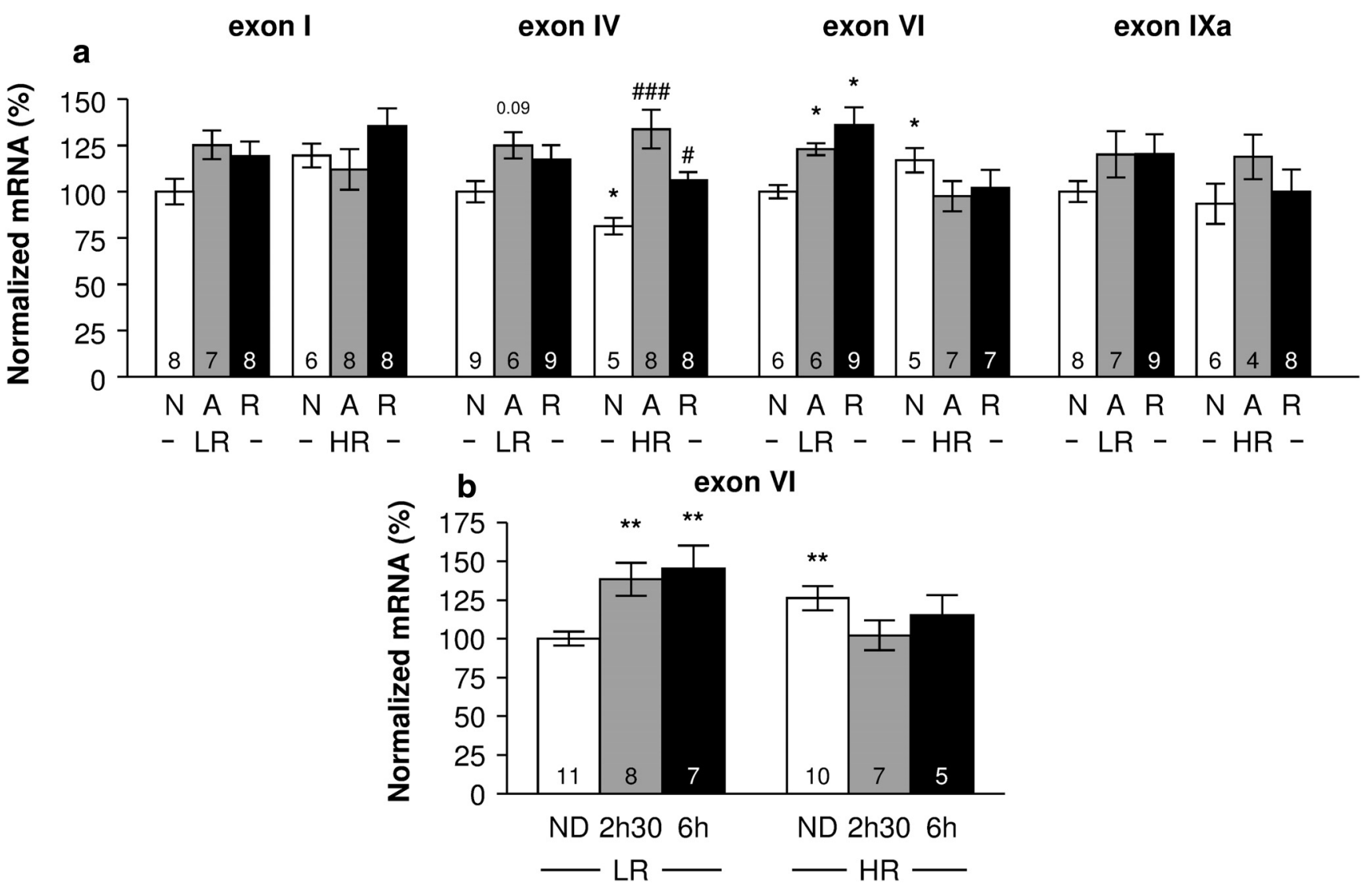

Figure 4. HR and LR animals exhibit individual differences in the regulation of BDNF mRNA transcripts in the hippocampus at baseline, and in response to social defeat. $a$, HR and LR animals were exposed to one (A) or four social defeat sessions ( $\mathrm{R}$ ), or to an empty cage of a Long-Evans rat (N), and were killed $2 \mathrm{~h}$ and 30 min later for analysis of BDNF mRNA transcripts I, IV, VI, and IXa (named exons I, IV, VI, and IXa) by real-time PCR. $\boldsymbol{b}$, HR and LR animals were exposed to an empty Long-Evans rat cage or to four defeat sessions and were killed $2 \mathrm{~h}$ and $30 \mathrm{~min}$ or $6 \mathrm{~h}$ after the end of the last defeat session. Half of the dorsal hippocampus was used for measuring mRNA levels of the BDNF exon VI transcript (b). The number of animals per group $(n=4-11)$ is shown within the columns, and the data are presented as the mean \pm SEM. Data were analyzed with a two-way ANOVA with HR/LR and defeat as independent factors, followed by Scheffé's post hoc test where appropriate. ${ }^{*} p<0.05,{ }^{* *} p<0.01$ versus LR-N; ${ }^{\#} p<0.05,{ }^{\# \#} p<0.001$ versus HR-N; Scheffé's post hoc test.

paired $t$ test: $t_{(12)}=0.11, p=0.914$; pERK2/ERK2: LR-N, $100 \pm$ $9.44 \%$; LR-R, $88.17 \pm 5.38 \%$; $\left.t_{(12)}=0.32, p=0.754\right]$, or $6 \mathrm{~h}$ after the end of the stress, when no individual differences or effect of stress were observed for ERK1 $\left(F_{(1,20)}=1.70, p=0.207\right.$ for $\mathrm{HR} / \mathrm{LR} ; F_{(1,20)}<1$ for defeat; and $F_{(1,20)}=2.13, p=0.159$ for the interaction; Fig. $3 d)$ or for ERK2 phosphorylation $\left(F_{(1,20)}=1.22\right.$, $p=0.282$ for HR/LR; and $F_{(1,20)}<1$ for defeat and the interaction; Fig. $3 d$ ). In line with $b d n f$ mRNA and protein levels, the analysis of CREB phosphorylation revealed individual differences both at baseline and in response to social defeat (Fig. 3b). While HR rats had higher baseline CREB phosphorylation than LR rats, CREB was phosphorylated following repeated defeat only in LR rats (two-way ANOVA: $F_{(1,34)}=7.41, p=0.010$ for HR/LR; $F_{(2,34)}<1$ for defeat; and $F_{(2,34)}=1.12, p=0.339$ for the interaction; Fig. $3 b$ ).

HR and LR rats therefore display marked individual differences regarding the activation of BDNF signaling. LR animals responded to a repeated defeat procedure with lower inactive TrkB.T1 receptor mRNA compared with the active TrkB.FL isoform, associated with a marked increase in TrkB phosphorylation $(+113 \%)$, which is an indicator of BDNF release. Such TrkB activation subsequently activates an intracellular signaling pathway involving Akt and CREB, which promotes neuronal survival and plasticity. HR animals, despite a higher phosphorylation of TrkB and CREB at baseline, failed to present with such a response to social defeat.

\section{Social defeat induces an exon-specific regulation of the} bdnf gene

From our previous observations, HR and LR animals exhibit a differential BDNF regulation mediating their vulnerability or resilience to social defeat. To investigate the underlying molecular mechanisms, we conducted an analysis of the hippocampal $b d n f$ gene regulation at baseline, and at $2 \mathrm{~h}$ and 30 min following social defeat. In rodents, as in humans, the $b d n f$ gene is composed of several noncoding exons, each one regulated by its own promoter and responding to different stimuli (Aid et al., 2007). We therefore analyzed the respective regulation of several $b d n f$ transcripts, namely, exons I, IV, VI, and IXa, based on their high abundance in the rat hippocampus, as well as their ability to be regulated by neuronal activity, antidepressant treatments, and social defeat (Tsankova et al., 2004, 2006; Aid et al., 2007).

While neither exon I (two-way ANOVA: $F_{(1,39)}=1.14$, $p=0.292$ for HR/LR; $F_{(2,39)}=2.09, p=0.137$ for defeat; and $F_{(2,39)}=2.18, p=0.126$ for the interaction; Fig. $\left.4 b\right)$ nor exon IXa (two-way ANOVA: $F_{(1,36)}=1.03, p=0.316$ for HR/LR; $F_{(2,36)}=$ $1.91, p=0.162$ for defeat; and $F_{(2,36)}<1$ for the interaction; Fig. $4 a$ ) were significantly affected by the HR/LR phenotype or exposure to social defeat, individual differences were observed for exons IV and VI. Although HR animals showed lower exon IV mRNA levels than LR individuals at baseline, both phenotypes exhibited a similar profile of upregulation following defeat, which was more pronounced after an acute exposure (two-way 
ANOVA: $F_{(1,39)}=1.28, p=0.264$ for HR/LR; $F_{(2,39)}=12.26, p<$ 0.001 for defeat; and $F_{(2,39)}=1.67, p=0.201$ for the interaction; Fig. $4 a$ ). Interestingly, the exon VI mRNA level analysis revealed a profile of regulation similar to the pan-BDNF mRNA levels. Indeed, while HR animals had higher exon VI mRNA levels than their LR counterpart at baseline $(+17 \%)$, only LR animals presented with an upregulation following social defeat, to the same extent as pan-BDNF (A: +23\%; R: $+33 \%$; two-way ANOVA: $F_{(1,34)}=4.48, p=0.042$ for HR/LR; $F_{(2,34)}=1.04, p=0.363$ for defeat; and $F_{(2,34)}=5.23, p=0.010$ for the interaction; Fig. $4 a$ ). Therefore, exon VI mRNA expression appears to be the main contributor to the differential regulation of pan-BDNF mRNA levels measured between HR and LR rats.

Interestingly, in repeatedly defeated LR rats, the $b d n f$ exon VI mRNA upregulation was maintained for at least $6 \mathrm{~h}$ after the last defeat session, while it remained unaffected in $\mathrm{HR}$ rats (two-way ANOVA: $F_{(1,42)}=2.79, p=0.102$ for HR/LR; $F_{(2,42)}=1.52, p=$ 0.230 for defeat; and $F_{(2,42)}=7.26, p=0.002$ for the interaction; Fig. $4 b)$. This suggests that $b d n f$ regulation in HR rats is absent, rather than delayed. Moreover, the $b d n f$ exon VI transcripts levels at $2 \mathrm{~h}$ and $30 \mathrm{~min}$, and up to $6 \mathrm{~h}$ following repeated social defeat, were negatively correlated with the locomotor score in a novel environment $\left(r=-0.608, p=0.0125, R^{2}=0.37\right.$ at the $2 \mathrm{~h}$ and 30 min time point; $r=-0.580, p=0.0480, R^{2}=0.336$ at the $6 \mathrm{~h}$ time point; data not shown). Individual differences in response to a novel environment therefore predict subsequent hippocampal levels of $b d n f$ exon VI transcript following repeated social defeat.

Altogether, these data reveal individual differences in the regulation of hippocampal BDNF between HR and LR rats. Despite having lower BDNF levels than HR rats at baseline, the resilient LR animals exhibited a significant upregulation of both $b d n f$ exon VI mRNA and protein levels following social defeat, while HR rats failed to display this physiological response.

\section{Differential vulnerability to social defeat is associated with a differential regulation of histone modifications at the $b d n f$ promoter 6}

Following our previous observations, we established that the differential BDNF regulation between HR and LR rats mediated their differential vulnerability to social defeat. As both the BDNF protein and mRNA levels, involving mainly exon VI, were affected, this led us to investigate whether HR and LR animals exhibited a differential transcriptional regulation of $b d n f$ exon VI at baseline and in response to social defeat. The promoterspecific regulation of $b d n f$ transcription in the hippocampus following social defeat and antidepressant treatment has been associated with local alteration of histone $\mathrm{H} 3$ acetylation, as well as K4 and K9 methylation (Tsankova et al., 2006), demonstrating a crucial role played by the epigenetic regulation of $b d n f$ promoters. Moreover, H3K9 methylation, a histone mark associated with transcriptional repression, has recently been demonstrated in the NAcc to play a major role in response to antidepressants and susceptibility to chronic social defeat (Wilkinson et al., 2009). Using chromatin immunoprecipitation assays, we thus measured the levels of $\mathrm{H} 3 \mathrm{~K} 4 \mathrm{me}^{2}$ and AcK9K14H3, both associated with transcriptional initiation, as well as of $\mathrm{H} 3 \mathrm{~K} 9 \mathrm{me}^{2}$ at the bdnf promoter 6 .

In line with the regulation of $b d n f$ exon VI mRNA levels, LR rats exhibited higher levels of both activation marks $\left(\mathrm{H} 3 \mathrm{~K} 4 \mathrm{me}^{2}\right.$ and AcK9K14H3) following social defeat, whereas HR animals did not, despite higher baseline levels (two-way ANOVA: $\mathrm{H} 3 \mathrm{~K} 4 \mathrm{me}^{2}: F_{(1,21)}=1.86, p=0.187$ for HR/LR; $F_{(2,21)}=2.78, p=$ 0.084 for defeat; and $F_{(2,21)}=4.54, p=0.023$ for the interaction;
AcK9K14H3: $F_{(1,24)}=4.75, p=0.039$ for HR/LR; $F_{(2,24)}<1$ for defeat; and $F_{(2,24)}=3.98, p=0.032$ for the interaction; Fig. $5 a$ ). This upregulation was associated with an opposite regulation of repressive histone marks in $\mathrm{LR}$ rats, as $\mathrm{H} 3 \mathrm{~K} 9 \mathrm{me}^{2}$ levels were reduced following both acute and repeated social defeat. In HR rats, $\mathrm{H} 3 \mathrm{~K} 9 \mathrm{me}^{2}$ remained unchanged after social defeat, despite lower levels than LR rats at baseline (two-way ANOVA: $F_{(1,24)}=12.94$, $p=0.001$ for HR/LR; $F_{(2,24)}=3.75, p=0.038$ for defeat; and $F_{(2,24)}=2.68, p=0.088$ for the interaction; Fig. $\left.5 b\right)$. In agreement with previous observations in mice (Tsankova et al., 2006), no significant differences in the levels of DNA methylation at $b d n f \mathrm{P} 6$ were observed between HR and LR animals, neither at baseline nor in response to a repeated social defeat paradigm $(4.18 \pm$ $0.23 \%$ for LR-N; $4.51 \pm 0.22 \%$ for LR-R; $4.25 \pm 0.26 \%$ for HR-N; and $4.31 \pm 0.38 \%$ for HR-R; two-way ANOVA: $F_{(1,19)}<1$ for all effects). These results demonstrate that the differential regulation of $b d n f$ exon VI mRNA between HR and LR animals is associated with a coherent regulation of histone modifications at the $b d n f$ promoter 6 (Fig. 6).

\section{A coherent differential regulation of epigenetic factors in $\mathrm{HR}$ and LR animals at baseline and following social defeat}

Following our previous experiments, we conducted an investigation of the epigenetic factors directly regulating the acetylation and methylation of histone H3. The mRNA levels of the H3K4specific methyltransferase Mll1, the K-acetyltransferase CBP, as well as the H3K9-specific demethylase Kdm3a (Milne et al., 2002; Allis et al., 2007; Gaub et al., 2010), were thus measured in the hippocampus $2 \mathrm{~h}$ and $30 \mathrm{~min}$ after the last defeat session.

In accordance to $\mathrm{H} 3 \mathrm{~K} 4 \mathrm{me}^{2}$ and $\mathrm{AcK} 9 \mathrm{~K} 14 \mathrm{H} 3$ regulation, LR animals exhibited higher levels of both Mll1 and CBP following social defeat, whereas HR animals did not, despite higher baseline levels (two-way ANOVA: Mll1: $F_{(1,36)}=9.00, p=0.005$ for HR/ LR; $F_{(2,36)}=3.12, p=0.056$ for defeat; and $F_{(2,36)}=1.43, p=$ 0.253 for the interaction; CBP: $F_{(1,39)}=10.04, p=0.003$ for HR/LR; $F_{(2,39)}=2.17, p=0.127$ for defeat; and $F_{(2,39)}<1$ for the interaction; Fig. $5 c$ ). Interestingly, no significant or coherent variations in mRNA level coding for the K-acetyltransferases KAT2B and KAT5 (also known as PCAF and Tip60, respectively) were detected, strengthening the involvement of CBP in histone acetylation at $b d n f$ P6 in the hippocampus following social defeat (Table 2). Although no differences were observed between nondefeated animals, LR animals, but not HR animals, exhibited an upregulation of Kdm3a mRNA levels following acute defeat (Fig. $5 d$ ), coherent with the lower $\mathrm{H} 3 \mathrm{~K} 9 \mathrm{me}^{2}$ at the $b d n f$ promoter 6 observed in the same condition (Fig. 5b). However, Kdm3a mRNA levels returned to baseline following repeated defeat, suggesting that $\mathrm{Kdm} 3 \mathrm{a}$ is not involved in the maintenance of $\mathrm{H} 3 \mathrm{~K} 9 \mathrm{me}^{2}$ downregulation at bdnf P6 in LR animals (two-way ANOVA: $F_{(1,35)}<1$ for HR/LR; $F_{(2,35)}=4.14, p=0.024$ for defeat; and $F_{(2,35)}=3.70, p=0.035$ for the interaction). Nevertheless, following repeated defeat, Kdm3a mRNA levels were upregulated in $\mathrm{HR}$ rats and significantly higher than their LR counterparts, which is coherent with the trend for lower $\mathrm{H} 3 \mathrm{~K} 9 \mathrm{me}^{2}$ levels observed in HR rats compared with LR rats following repeated defeat (Fig. $5 b$ ).

Together, these data suggest that the individual differences in the regulation of $b d n f$ exon VI mRNA observed between HR and LR animals at baseline and in response to social defeat result from a coherent regulation of epigenetic factors, including Mll1 and $\mathrm{CBP}$, as well as Kdm3a to a lesser extent, modulating $b d n f$ transcription in a coordinated manner. 

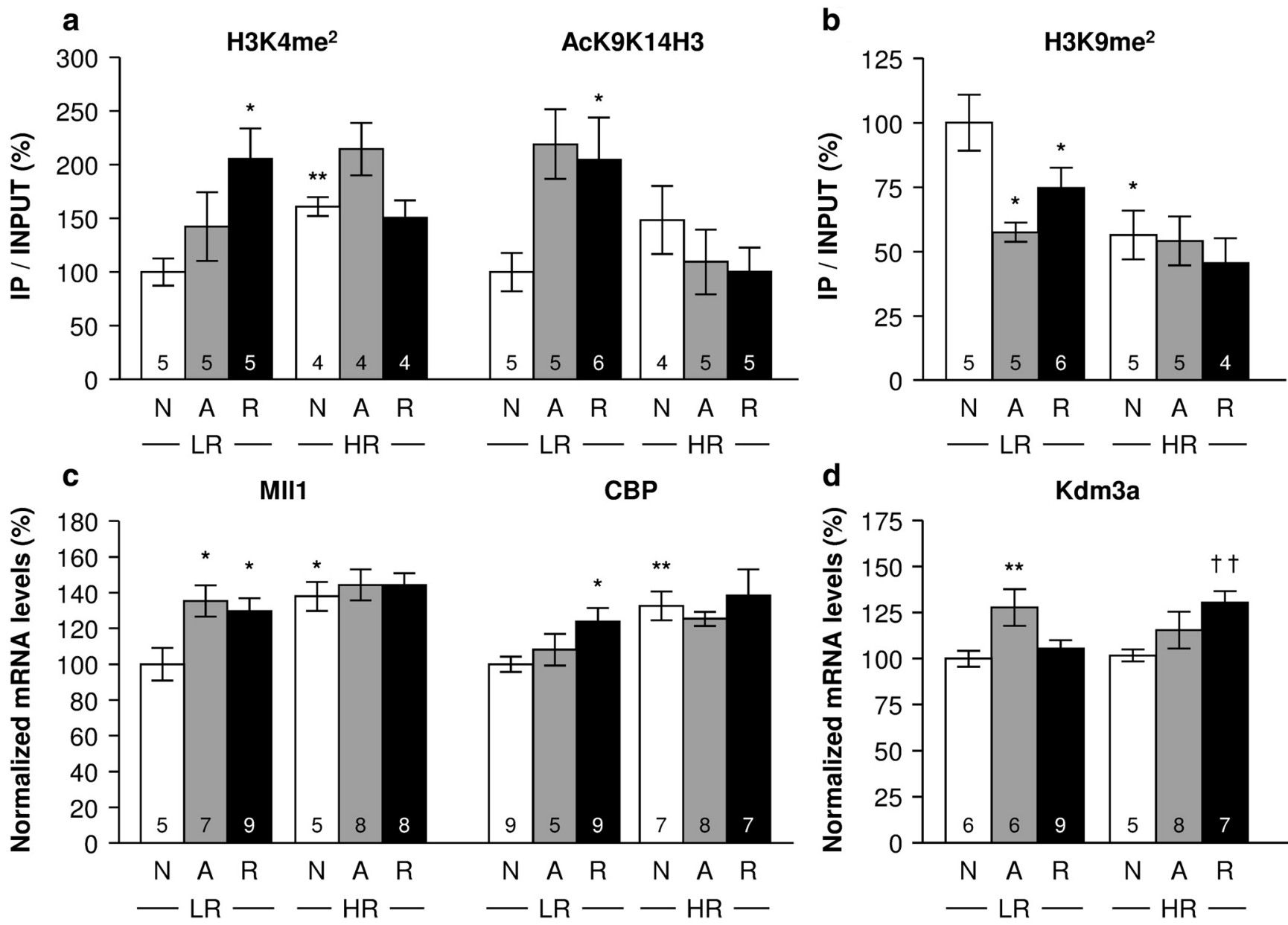

Figure 5. HR and LR animals exhibit individual differences in the epigenetic regulation of the BDNF promoter 6 , associated with a coherent regulation of relevant epigenetic factors. $\boldsymbol{a}-\boldsymbol{d}$, HR and LR animals were exposed to one ( $\mathrm{A}$ ) or four social defeat sessions (R), or to an empty cage of a Long-Evans rat (N), and were killed $2 \mathrm{~h}$ and 30 min later for the measure of histone modifications at the BDNF promoter 6 by chromatin immunoprecipitation $(\boldsymbol{a}, \boldsymbol{b})$ or mRNA levels for relevant epigenetic factors by real-time $\mathrm{PCR}(\boldsymbol{c}, \boldsymbol{d})$. The number of animals per group $(n=4-9)$ is shown within the columns, and the data are presented as the mean \pm SEM. Data were analyzed with a two-way ANOVA with HR/LR and defeat as independent factors, followed by Scheffe's post hoc test where appropriate. ${ }^{*} p<0.05,{ }^{* *} p<0.01$ versus LR-N; and ${ }^{t \dagger} p<0.01$ versus same defeat treatment in LR animals; Scheffé's post hoc test.

\section{Discussion}

In the present study, we highlight a critical role played by hippocampal BDNF and its epigenetic regulation in the individual differences in vulnerability to psychosocial stress. We have used an animal model of high and low novelty seeking that predicts subsequent vulnerability to social defeat. While the BDNF levels in the vulnerable high novelty seekers (HRs) are not altered by the psychosocial stress, the resilient low novelty seekers (LRs) exhibited an upregulation of BDNF exon VI mRNA and protein levels. This $b d n f$ upregulation in LR animals was associated with a putative higher sensitivity to BDNF release and activation of the TrkB-AKT-CREB pathway. Importantly, preventing activation of BDNF signaling in LR rats, or inducing it in HR rats, was sufficient to reverse their respective resilience or vulnerability to social defeat. Finally, the differential BDNF regulation between $\mathrm{HR}$ and LR rats was associated with a coordinated epigenetic regulation specific to $b d n f$ promoter 6 . Together, these data demonstrate that upregulation, through exon VI, of BDNF expression and subsequent signaling in response to social defeat protected LR rats against the development of depressive-like symptoms, while HR rats, lacking such upregulation, were vulnerable.

Relying solely on a psychosocial stress, social defeat is an ethologically relevant model for depression inducing behavioral, met- abolic, and endocrine alterations related to depression (Nestler and Hyman, 2010). However, unlike other models such as CMS, these effects are also associated with anxiety-like symptoms, reproducing the comorbidity in humans between depression and anxiety disorders. Nevertheless, social defeat is repeatedly used to study individual differences in stress vulnerability. Interestingly, both vulnerable and resilient animals develop anxiety-like behaviors (Krishnan et al., 2007), a phenomenon also observed in the HR/LR model where both HR and LR animals develop anxietylike behaviors, while HR, but not LR rats, exhibit anhedonia and alterations in body weight gain (Duclot et al., 2011). Social defeat can thus specifically reveal individual differences in vulnerability to depression, but the involvement of hippocampal BDNF in this process remains to be clearly defined.

In the hippocampus, the regulation of BDNF expression by chronic social stress is unclear, with some groups reporting a reduction, some reporting an increase, and others reporting no changes, very likely resulting from differences in experimental designs (Pizarro et al., 2004; Tsankova et al., 2006; Lagace et al., 2010; Coppens et al., 2011). In our study, LR rats, but not HR rats, exhibited a BDNF upregulation following social defeat, similar to the effects of antidepressants on BDNF expression (Duman and Monteggia, 2006), which suggested that the BDNF upregulation 


\section{LR rats}

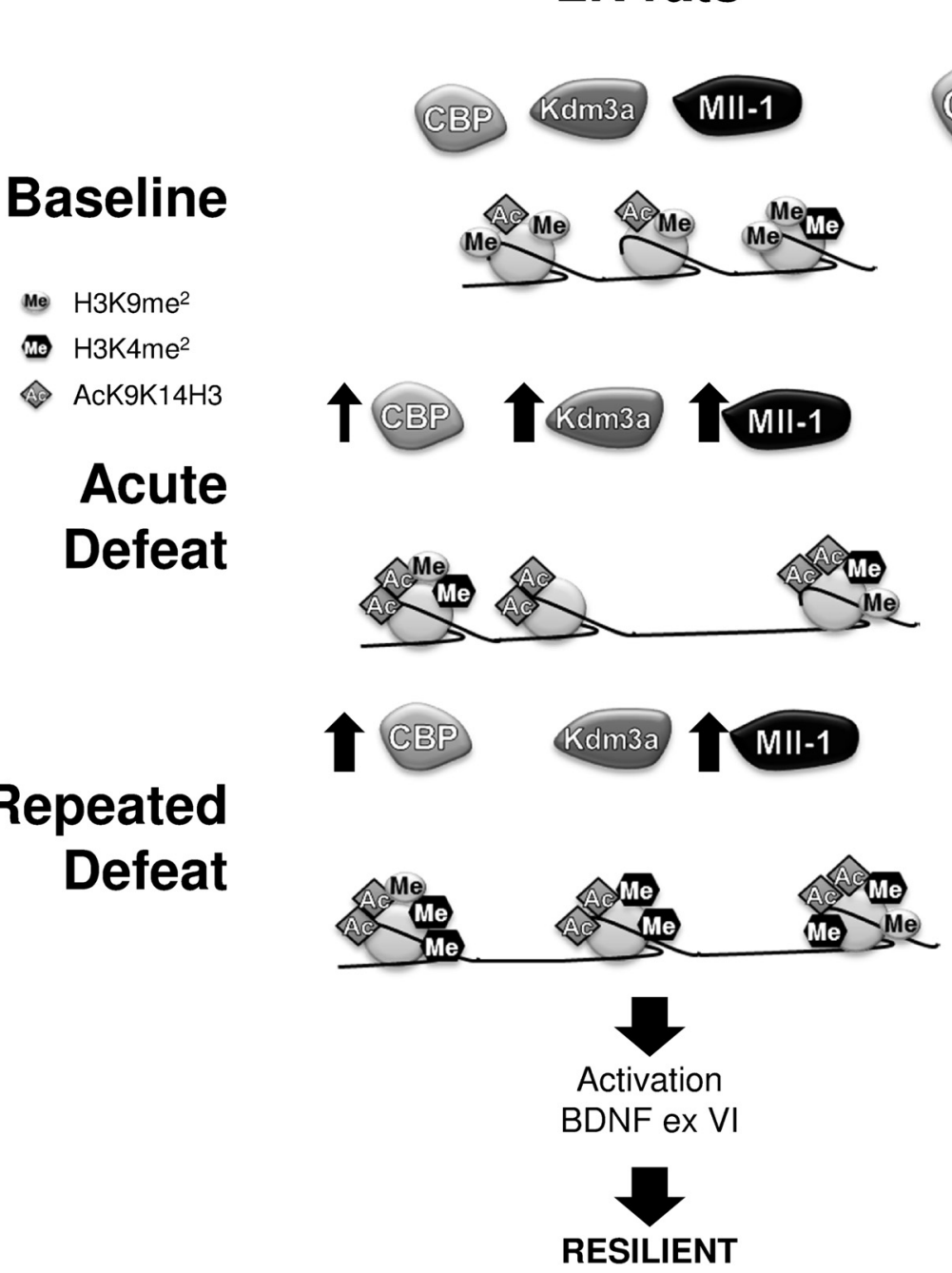

HR rats

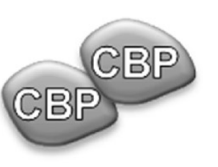

MII-1 MII-1
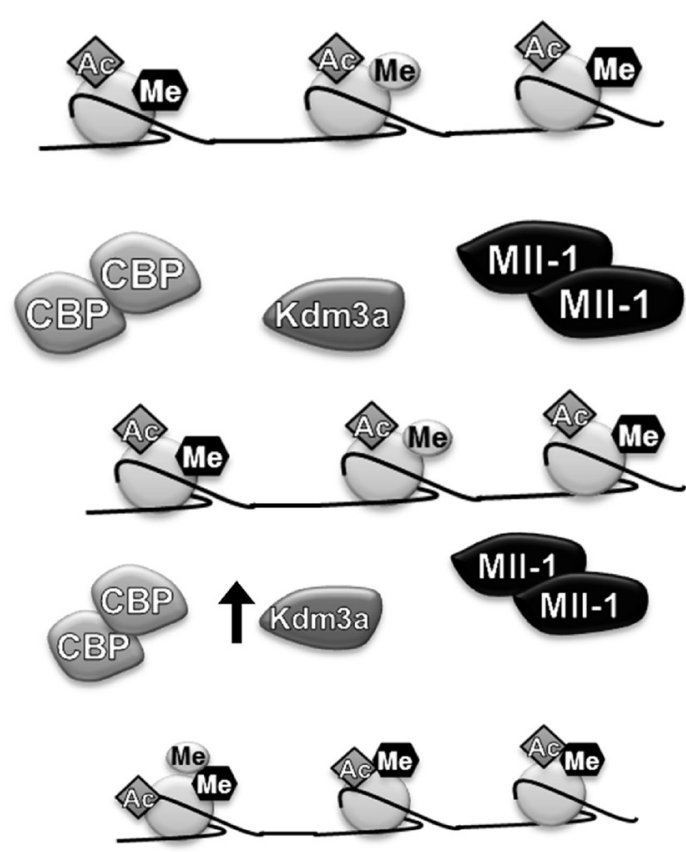

No activation BDNF ex VI

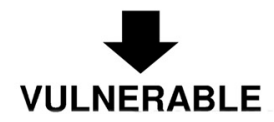

Figure 6. Low-novelty-seeking animals (LRs) exhibit a coordinated epigenetic regulation of the bdnf promoter 6 following social defeat, coherent with a transcriptional activation, whereas high-novelty-seeking animals (HRs) do not. The hippocampal bdnf promoter 6 is represented, associated with its regulation of histone modifications and corresponding epigenetic factors at baseline (top) and following acute (middle) or repeated defeat (bottom) in LR (left) and HR (right) animals. Following the first defeat session, LR animals display an upregulation of the K-acetyltransferases

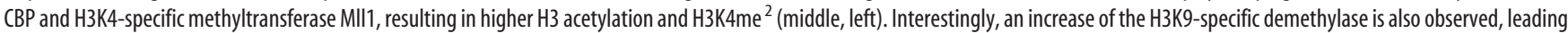
to the removal of the repressive $\mathrm{H} 3 \mathrm{~K}_{9 \mathrm{me}}{ }^{2}$, which, unlike Kdm3a, is maintained following repeated exposure to the defeat (bottom, left). Similar to H3K9me ${ }^{2}$, the increases of H3K4me ${ }^{2}$, AcK9K14H3, MII1, and CBP are also maintained after repeated defeat, promoting transcriptional activation of BDNF exon VI and resilience to social defeat. Compared with LR animals, HR animals exhibit at baseline (top, right) higher H3K4me ${ }^{2}$, CBP, and MII1 levels, which, associated with lower H3K9me ${ }^{2}$, result in higher BDNF exon VI mRNA levels. Following repeated social defeat, however, only a slight increase in Kdm3a is observed but does not induce any further transcriptional activation, therefore leaving HR animals vulnerable to the social defeat. Arrows indicate increases in mRNA levels proportional to their width, compared with nondefeated animals (baseline) of the same phenotype.

Table 2. mRNA levels of K-acetyltransferase enzymes in the hippocampus, $2 \mathrm{~h}$ and $30 \mathrm{~min}$ after the last defeat exposure (\%)

\begin{tabular}{|c|c|c|c|c|c|c|}
\hline \multirow{2}{*}{ 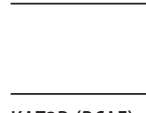 } & \multicolumn{3}{|l|}{ LR } & \multicolumn{3}{|l|}{ HR } \\
\hline & $\mathrm{N}$ & A & $\mathrm{R}$ & $\mathrm{N}$ & A & $\mathrm{R}$ \\
\hline KAT2B (PCAF) & $100.0 \pm 2.36$ & $107.1 \pm 4.57$ & $102.4 \pm 10.95$ & $93.5 \pm 3.46$ & $125.7 \pm 12.52^{*}$ & $96.0 \pm 4.95$ \\
\hline KAT5 (Tip60) & $100.0 \pm 3.33$ & $110.8 \pm 11.26$ & $114.8 \pm 5.66$ & $105.1 \pm 9.43$ & $116.2 \pm 5.05$ & $98.7 \pm 6.51$ \\
\hline
\end{tabular}

mRNA levels of histone acetyltransferases in the hippocampus of LR and HRanimals, 2 h and 30 min following exposure to one (A) and four (R) defeat sessions, or an empty Long-Evans rat cage ( $N$ ). Data ( $n=4-10$ per group) are represented as the mean \pm SEM, and were analyzed with a two-way ANOVA with HR/LR and defeat as independent factors, followed by Scheffé's post hoc test where appropriate. * $p<0.01$ versus HR-N, Scheffé's post hoc test.

was mediating LR resilience. In agreement with this hypothesis, preventing the subsequent activation of BDNF signaling in the DGs of LR rats before each defeat session promoted vulnerability, whereas its activation was sufficient to promote resilience. Interestingly, this also suggested that following social stress, LR animals present with an endogenous antidepressant-like response, as further supported by the differential regulation of $b d n f$ transcripts. Antidepressant treatments and various stressors regulate
BDNF expression through a specific regulation of $b d n f$ transcripts. Although the regulation of transcript IXa in the hippocampus is poorly documented, an acute footshock stress triggers in the hippocampus an upregulation of $b d n f$ transcripts I and IV, but not VI, through local increase in histone acetylation (Fuchikami et al., 2010). Moreover, while exon VI mRNA levels in the hippocampus are increased following acute forced-swim stress only in animals pretreated with an antidepressant, exon IV 
mRNA levels are increased by this stress regardless of prior antidepressant treatment (Molteni et al., 2009). Furthermore, exercise or repeated treatment with fluoxetine or reboxetine, all exhibiting antidepressant properties, upregulate the hippocampal mRNA levels of transcript VI but not IV (Baj et al., 2012). These observations therefore suggest a specific involvement of transcript IV in the response to stress itself, while transcript VI upregulation might exert a protective function. Accordingly, we detected a similar response to social stress in both LR and HR rats, where the $b d n f$ transcript IV was strongly upregulated by the acute stress regardless of the phenotype, whereas transcript VI mRNA upregulation was observed only in the resilient LR rats. Therefore, in addition to strengthening the role of hippocampal BDNF response in determining vulnerability to physical, environmental, as well as psychosocial stress (Blugeot et al., 2011; Taliaz et al., 2011), our study highlights a specific role of transcript VI and its transcriptional regulation in these effects.

Thus, it appears critical to understand the molecular bases of $b d n f$ transcript VI regulation. Interestingly, we uncovered a coherent and coordinated epigenetic regulation of its promoter 6 . Indeed, LR and HR rats exhibited coherent individual differences in both histone $\mathrm{H} 3$ acetylation and methylation and their relevant enzymes. A similar $\mathrm{H} 3$ hyperacetylation at the $b d n f$ promoter 6 was observed in the hippocampus following social defeat, but only under chronic antidepressant treatment (Tsankova et al., 2006), strengthening the proposed protective role of the $b d n f$ transcript VI. Nevertheless, although their simultaneous recruitment at $b d n f$ promoters remains to be confirmed, our results suggest for the first time a coordinated role for Mll1 and CBP in the regulation of $b d n f$. CBP can be rapidly recruited to the $b d n f$ promoter 6 in the rat hippocampus (Sui et al., 2010), and its overexpression in the mouse brain upregulates hippocampal BDNF levels (Caccamo et al., 2010), demonstrating that CBP can directly promote $b d n f$ exon VI transcription. Although Mll1 has already been associated with the regulation of cerebral plasticity (Gupta et al., 2010), its direct involvement in $b d n f$ transcription remains unknown. However, in accordance with our observations, several lines of evidence suggest that Mll1 and CBP can directly interact (De Guzman et al., 2006; Arai et al., 2010), which could therefore explain the concurrent histone $\mathrm{H} 3$ acetylation and K4 methylation observed in our study and previously (Zhang et al., 2004).

In combination with the alteration of permissive histone modifications, we also uncovered a coherent regulation of repressive marks. Indeed, LR but not $\mathrm{HR}$ rats exhibited lower $\mathrm{H} 3 \mathrm{~K} 9 \mathrm{me}^{2}$ levels at $b d n f$ promoter 6 following social defeat, revealing a coordinated epigenetic regulation facilitating $b d n f$ exon VI transcription, where permissive and repressive histone modifications are increased or reduced, respectively. Without consideration of individual variability, another report found no changes in $\mathrm{H} 3 \mathrm{~K} 9 \mathrm{me}^{2}$ at $b d n f$ promoters in the mouse hippocampus following chronic social defeat or antidepressant treatment (Tsankova et al., 2006). Nevertheless, $\mathrm{H} 3 \mathrm{~K} 9 \mathrm{me}^{2}$ has been proposed as a critical regulator of response to social defeat and antidepressants in other brain structures. Indeed, in the mouse NAcc, a chronic antidepressant treatment reverses the genome-wide pattern of $\mathrm{H} 3 \mathrm{~K} 9 \mathrm{me}^{2}$ altered by social defeat to resemble the pattern of resilient animals (Wilkinson et al., 2009). Furthermore, overexpression of the histone methyltransferases G9a or Setdb1 in the NAcc or the forebrain, respectively, induces antidepressant effects (Jiang et al., 2010b; Covington et al., 2011). It would thus be interesting to investigate the specific involvement of these epige- netic factors in the differential $b d n f$ regulation observed in HR and LR animals.

Functionally, the individual differences between LR and HR rats in their vulnerability to social defeat are mediated by a differential activation of BDNF signaling. In the resilient LR rats, the BDNF upregulation following social defeat was associated with phosphorylation of CREB following TrkB activation, partly through induction of a pathway involving PI3K-Akt but not MSK1. However, we observed a disconnection, at baseline, between Akt and CREB activation in HR rats, with higher pCREB but not pAkt levels. It is noteworthy that TrkB.FL can also induce CREB phosphorylation through the PLC $\gamma$-CaMKII pathway (Cunha et al., 2010), which could therefore explain the higher baseline phosphorylation of CREB in HR rats. However, although classic antidepressants seem to depend on intact monoamine levels to preferentially activate the PLC $\gamma$-CaMKII pathway (Saarelainen et al., 2003; Rantamäki et al., 2007), BDNF and 7,8-DHF, both promoting stress resilience, as well as other nonclassical antidepressant approaches, activate the PI3K-Akt pathway (Cunha et al., 2010; Nakano et al., 2010; Furmaga et al., 2012; Gupta et al., 2013). Interestingly, overexpression of the inactive TrkB.T1 isoform promotes vulnerability to social defeat in mice and prevents antidepressants' efficacy (Saarelainen et al., 2003; Razzoli et al., 2011), which strongly suggests that the TrkB.T1 downregulation in LR animals after social defeat promoted their resilience. Despite a higher baseline, HR animals failed to further enhance hippocampal BDNF signaling following defeat, as observed in the resilient LR rats, strengthening the importance of BDNF response, rather than its absolute levels, in mediating stress resilience. In support, TrkB phosphorylation after social defeat is negatively correlated with locomotion in a novel environment, which predicts subsequent vulnerability to social defeat. Furthermore, preventing or inducing BDNF signaling activation in LR and HR rats, respectively, was sufficient to reverse their resilient and vulnerable phenotypes. In rats, novelty seeking is a good predictor of subsequent individual differences in vulnerability to stress, with low novelty seekers (LRs) and high novelty seekers (HRs) being less and more vulnerable, respectively. Here we demonstrate that such psychosocial stress resilience requires hippocampal BDNF upregulation, underlined by a specific and coordinated epigenetic upregulation of exon VI transcription. In addition to strengthening the role of BDNF as a critical regulator of stress resilience, the specific involvement of $b d n f$ exon VI and its epigenetic regulation is now emphasized.

\section{References}

Adachi M, Barrot M, Autry AE, Theobald D, Monteggia LM (2008) Selective loss of brain-derived neurotrophic factor in the dentate gyrus attenuates antidepressant efficacy. Biol Psychiatry 63:642-649. CrossRef Medline

Aid T, Kazantseva A, Piirsoo M, Palm K, Timmusk T (2007) Mouse and rat BDNF gene structure and expression revisited. J Neurosci Res 85:525535. CrossRef Medline

Allis CD, Berger SL, Cote J, Dent S, Jenuwien T, Kouzarides T, Pillus L, Reinberg D, Shi Y, Shiekhattar R, Shilatifard A, Workman J, Zhang Y (2007) New nomenclature for chromatin-modifying enzymes. Cell 131: 633-636. CrossRef Medline

Arai M, Dyson HJ, Wright PE (2010) Leu628 of the KIX domain of CBP is a key residue for the interaction with the MLL transactivation domain. FEBS Lett 584:4500-4504. CrossRef Medline

Arthur JS, Fong AL, Dwyer JM, Davare M, Reese E, Obrietan K, Impey S (2004) Mitogen- and stress-activated protein kinase 1 mediates cAMP response element-binding protein phosphorylation and activation by neurotrophins. J Neurosci 24:4324-4332. CrossRef Medline

Baj G, D’Alessandro V, Musazzi L, Mallei A, Sartori CR, Sciancalepore M, Tardito D, Langone F, Popoli M, Tongiorgi E (2012) Physical exercise and antidepressants enhance BDNF targeting in hippocampal CA3 den- 
drites: further evidence of a spatial code for BDNF splice variants. Neuropsychopharmacology 37:1600-1611. CrossRef Medline

Bergström A, Jayatissa MN, Mørk A, Wiborg O (2008) Stress sensitivity and resilience in the chronic mild stress rat model of depression; an in situ hybridization study. Brain Res 1196:41-52. CrossRef Medline

Berton O, McClung CA, Dileone RJ, Krishnan V, Renthal W, Russo SJ, Graham D, Tsankova NM, Bolanos CA, Rios M, Monteggia LM, Self DW, Nestler EJ (2006) Essential role of BDNF in the mesolimbic dopamine pathway in social defeat stress. Science 311:864-868. CrossRef Medline

Björkqvist K (2001) Social defeat as a stressor in humans. Physiol Behav 73:435-442. CrossRef Medline

Black DW, Shaw M, McCormick B, Bayless JD, Allen J (2012) Neuropsychological performance, impulsivity, ADHD symptoms, and novelty seeking in compulsive buying disorder. Psychiatry Res 200:581-587. CrossRef Medline

Blugeot A, Rivat C, Bouvier E, Molet J, Mouchard A, Zeau B, Bernard C, Benoliel JJ, Becker C (2011) Vulnerability to depression: from brain neuroplasticity to identification of biomarkers. J Neurosci 31:12889-12899. CrossRef Medline

Bousiges O, Vasconcelos AP, Neidl R, Cosquer B, Herbeaux K, Panteleeva I, Loeffler JP, Cassel JC, Boutillier AL (2010) Spatial memory consolidation is associated with induction of several lysine-acetyltransferase (histone acetyltransferase) expression levels and $\mathrm{H} 2 \mathrm{~B} / \mathrm{H} 4$ acetylationdependent transcriptional events in the rat hippocampus. Neuropsychopharmacology 35:2521-2537. CrossRef Medline

Caccamo A, Maldonado MA, Bokov AF, Majumder S, Oddo S (2010) CBP gene transfer increases BDNF levels and ameliorates learning and memory deficits in a mouse model of Alzheimer's disease. Proc Natl Acad Sci U S A 107:22687-22692. CrossRef Medline

Calvo N, Cecchi M, Kabbaj M, Watson SJ, Akil H (2011) Differential effects of social defeat in rats with high and low locomotor response to novelty. Neuroscience 183:81-89. CrossRef Medline

Carrier N, Kabbaj M (2012) Extracellular signal-regulated kinase 2 signaling in the hippocampal dentate gyrus mediates the antidepressant effects of testosterone. Biol Psychiatry 71:642-651. CrossRef Medline

Coppens CM, Siripornmongcolchai T, Wibrand K, Alme MN, Buwalda B, de Boer SF, Koolhaas JM, Bramham CR (2011) Social defeat during adolescence and adulthood differentially induce BDNF-regulated immediate early genes. Front Behav Neurosci 5:72. CrossRef Medline

Covington HE 3rd, Vialou VF, LaPlant Q, Ohnishi YN, Nestler EJ (2011) Hippocampal-dependent antidepressant-like activity of histone deacetylase inhibition. Neurosci Lett 493:122-126. CrossRef Medline

Cunha C, Brambilla R, Thomas KL (2010) A simple role for BDNF in learning and memory? Front Mol Neurosci 3:1. CrossRef Medline

De Guzman RN, Goto NK, Dyson HJ, Wright PE (2006) Structural basis for cooperative transcription factor binding to the CBP coactivator. J Mol Biol 355:1005-1013. CrossRef Medline

Devi L, Ohno M (2012) 7,8-dihydroxyflavone, a small-molecule TrkB agonist, reverses memory deficits and BACE1 elevation in a mouse model of Alzheimer's disease. Neuropsychopharmacology 37:434-444. CrossRef Medline

Duclot F, Hollis F, Darcy MJ, Kabbaj M (2011) Individual differences in novelty-seeking behavior in rats as a model for psychosocial stress-related mood disorders. Physiol Behav 104:296-305. CrossRef Medline

Duman RS, Monteggia LM (2006) A neurotrophic model for stress-related mood disorders. Biol Psychiatry 59:1116-1127. CrossRef Medline

Fuchikami M, Yamamoto S, Morinobu S, Takei S, Yamawaki S (2010) Epigenetic regulation of BDNF gene in response to stress. Psychiatry Investig 7:251-256. CrossRef Medline

Furmaga H, Carreno FR, Frazer A (2012) Vagal nerve stimulation rapidly activates brain-derived neurotrophic factor receptor TrkB in rat brain. PLoS One 7:e34844. CrossRef Medline

Gaub P, Tedeschi A, Puttagunta R, Nguyen T, Schmandke A, Di Giovanni S (2010) HDAC inhibition promotes neuronal outgrowth and counteracts growth cone collapse through $\mathrm{CBP} / \mathrm{p} 300$ and $\mathrm{P} / \mathrm{CAF}$-dependent $\mathrm{p} 53$ acetylation. Cell Death Differ 17:1392-1408. CrossRef Medline

Givalois L, Naert G, Rage F, Ixart G, Arancibia S, Tapia-Arancibia L (2004) A single brain-derived neurotrophic factor injection modifies hypothalamo-pituitaryadrenocortical axis activity in adult male rats. Mol Cell Neurosci 27:280-295. CrossRef Medline

Gupta S, Kim SY, Artis S, Molfese DL, Schumacher A, Sweatt JD, Paylor RE,
Lubin FD (2010) Histone methylation regulates memory formation. J Neurosci 30:3589-3599. CrossRef Medline

Gupta VK, You Y, Li JC, Klistorner A, Graham SL (2013) Protective effects of 7,8-dihydroxyflavone on retinal ganglion and RGC-5 cells against excitotoxic and oxidative stress. J Mol Neurosci 49:96-104. CrossRef Medline

Haapasalo A, Sipola I, Larsson K, Akerman KE, Stoilov P, Stamm S, Wong G, Castren E (2002) Regulation of TRKB surface expression by brainderived neurotrophic factor and truncated TRKB isoforms. J Biol Chem 277:43160-43167. CrossRef Medline

Haenisch B, Bilkei-Gorzo A, Caron MG, Bönisch H (2009) Knockout of the norepinephrine transporter and pharmacologically diverse antidepressants prevent behavioral and brain neurotrophin alterations in two chronic stress models of depression. J Neurochem 111:403-416. CrossRef Medline

Hollis F, Duclot F, Gunjan A, Kabbaj M (2011) Individual differences in the effect of social defeat on anhedonia and histone acetylation in the rat hippocampus. Horm Behav 59:331-337. CrossRef Medline

Hoshaw BA, Malberg JE, Lucki I (2005) Central administration of IGF-I and BDNF leads to long-lasting antidepressant-like effects. Brain Res 1037: 204-208. CrossRef Medline

Jang SW, Liu X, Yepes M, Shepherd KR, Miller GW, Liu Y, Wilson WD, Xiao G, Blanchi B, Sun YE, Ye K (2010) A selective TrkB agonist with potent neurotrophic activities by 7,8-dihydroxyflavone. Proc Natl Acad Sci U S A 107:2687-2692. CrossRef Medline

Jiang M, Zhang Y, Fei J, Chang X, Fan W, Qian X, Zhang T, Lu D (2010a) Rapid quantification of DNA methylation by measuring relative peak heights in direct bisulfite-PCR sequencing traces. Lab Invest 90:282-290. CrossRef Medline

Jiang Y, Jakovcevski M, Bharadwaj R, Connor C, Schroeder FA, Lin CL, Straubhaar J, Martin G, Akbarian S (2010b) Setdb1 histone methyltransferase regulates mood-related behaviors and expression of the NMDA receptor subunit NR2B. J Neurosci 30:7152-7167. CrossRef Medline

Josefsson K, Merjonen P, Jokela M, Pulkki-Råback L, Keltikangas-Järvinen L (2011) Personality profiles identify depressive symptoms over ten years? A population-based study. Depress Res Treat 2011:431314. CrossRef Medline

Komatsu H, Ohara A, Sasaki K, Abe H, Hattori H, Hall FS, Uhl GR, Sora I (2011) Decreased response to social defeat stress in mu-opioid-receptor knockout mice. Pharmacol Biochem Behav 99:676-682. CrossRef Medline

Krishnan V, Han MH, Graham DL, Berton O, Renthal W, Russo SJ, Laplant Q, Graham A, Lutter M, Lagace DC, Ghose S, Reiseter R, Tannous P, Green TA, Neve RL, Chakravarty S, Kumar A, Eisch AJ, Self DW, Lee FS, et al. (2007) Molecular adaptations underlying susceptibility and resistance to social defeat in brain reward regions. Cell 131:391-404. CrossRef Medline

Lagace DC, Donovan MH, DeCarolis NA, Farnbauch LA, Malhotra S, Berton O, Nestler EJ, Krishnan V, Eisch AJ (2010) Adult hippocampal neurogenesis is functionally important for stress-induced social avoidance. Proc Natl Acad Sci U S A 107:4436-4441. CrossRef Medline

Liu X, Chan CB, Jang SW, Pradoldej S, Huang J, He K, Phun LH, France S, Xiao G, Jia Y, Luo HR, Ye K (2010) A synthetic 7,8-dihydroxyflavone derivative promotes neurogenesis and exhibits potent antidepressant effect. J Med Chem 53:8274-8286. CrossRef Medline

Milne TA, Briggs SD, Brock HW, Martin ME, Gibbs D, Allis CD, Hess JL (2002) MLL targets SET domain methyltransferase activity to Hox gene promoters. Mol Cell 10:1107-1117. CrossRef Medline

Mizoguchi H, Nakade J, Tachibana M, Ibi D, Someya E, Koike H, Kamei H, Nabeshima T, Itohara S, Takuma K, Sawada M, Sato J, Yamada K (2011) Matrix metalloproteinase- 9 contributes to kindled seizure development in pentylenetetrazole-treated mice by converting pro-BDNF to mature BDNF in the hippocampus. J Neurosci 31:12963-12971. CrossRef Medline

Molteni R, Calabrese F, Cattaneo A, Mancini M, Gennarelli M, Racagni G, Riva MA (2009) Acute stress responsiveness of the neurotrophin BDNF in the rat hippocampus is modulated by chronic treatment with the antidepressant duloxetine. Neuropsychopharmacology 34:1523-1532. CrossRef Medline

Nakano M, Osada K, Misonoo A, Fujiwara K, Takahashi M, Ogawa Y, Haga T, Kanai S, Tanaka D, Sasuga Y, Yanagida T, Asakura M, Yamaguchi N 
(2010) Fluvoxamine and sigma-1 receptor agonists dehydroepiandrosterone (DHEA)-sulfate induces the Ser473-phosphorylation of Akt-1 in PC12 cells. Life Sci 86:309-314. CrossRef Medline

Nestler EJ, Hyman SE (2010) Animal models of neuropsychiatric disorders. Nat Neurosci 13:1161-1169. CrossRef Medline

Nibuya M, Morinobu S, Duman RS (1995) Regulation of BDNF and trkB mRNA in rat brain by chronic electroconvulsive seizure and antidepressant drug treatments. J Neurosci 15:7539-7547. Medline

Niculescu MD, Craciunescu CN, Zeisel SH (2006) Dietary choline deficiency alters global and gene-specific DNA methylation in the developing hippocampus of mouse fetal brains. FASEB J 20:43-49. CrossRef Medline

Paxinos GWC, Watson SJ (1998) The rat brain in stereotaxic coordinates, Ed 3. San Diego: Academic.

Piazza PV, Deminière JM, Le Moal M, Simon H (1989) Factors that predict individual vulnerability to amphetamine self-administration. Science 245:1511-1513. CrossRef Medline

Pizarro JM, Lumley LA, Medina W, Robison CL, Chang WE, Alagappan A, Bah MJ, Dawood MY, Shah JD, Mark B, Kendall N, Smith MA, Saviolakis GA, Meyerhoff JL (2004) Acute social defeat reduces neurotrophin expression in brain cortical and subcortical areas in mice. Brain Res 1025: 10-20. CrossRef Medline

Rantamäki T, Hendolin P, Kankaanpää A, Mijatovic J, Piepponen P, Domenici E, Chao MV, Männistö PT, Castrén E (2007) Pharmacologically diverse antidepressants rapidly activate brain-derived neurotrophic factor receptor TrkB and induce phospholipase- $\mathrm{C}$ gamma signaling pathways in mouse brain. Neuropsychopharmacology 32:2152-2162. CrossRef Medline

Razzoli M, Domenici E, Carboni L, Rantamaki T, Lindholm J, Castrén E, Arban R (2011) A role for BDNF/TrkB signaling in behavioral and physiological consequences of social defeat stress. Genes Brain Behav 10:424433. CrossRef Medline

Roth TL, Zoladz PR, Sweatt JD, Diamond DM (2011) Epigenetic modification of hippocampal Bdnf DNA in adult rats in an animal model of posttraumatic stress disorder. J Psychiatr Res 45:919-926. CrossRef Medline

Saarelainen T, Hendolin P, Lucas G, Koponen E, Sairanen M, MacDonald E, Agerman K, Haapasalo A, Nawa H, Aloyz R, Ernfors P, Castrén E (2003) Activation of the TrkB neurotrophin receptor is induced by antidepressant drugs and is required for antidepressant-induced behavioral effects. J Neurosci 23:349-357. Medline

Schroeder M, Krebs MO, Bleich S, Frieling H (2010) Epigenetics and depression: current challenges and new therapeutic options. Curr Opin Psychiatry 23:588-592. CrossRef Medline

Shirayama Y, Chen AC, Nakagawa S, Russell DS, Duman RS (2002) Brainderived neurotrophic factor produces antidepressant effects in behavioral models of depression. J Neurosci 22:3251-3261. Medline

Sui L, Ren WW, Li BM (2010) Administration of thyroid hormone increases reelin and brain-derived neurotrophic factor expression in rat hippocampus in vivo. Brain Res 1313:9-24. CrossRef Medline

Taliaz D, Stall N, Dar DE, Zangen A (2010) Knockdown of brain-derived neurotrophic factor in specific brain sites precipitates behaviors associated with depression and reduces neurogenesis. Mol Psychiatry 15:80-92. CrossRef Medline

Taliaz D, Loya A, Gersner R, Haramati S, Chen A, Zangen A (2011) Resilience to chronic stress is mediated by hippocampal brain-derived neurotrophic factor. J Neurosci 31:4475-4483. CrossRef Medline

Tsankova NM, Kumar A, Nestler EJ (2004) Histone modifications at gene promoter regions in rat hippocampus after acute and chronic electroconvulsive seizures. J Neurosci 24:5603-5610. CrossRef Medline

Tsankova NM, Berton O, Renthal W, Kumar A, Neve RL, Nestler EJ (2006) Sustained hippocampal chromatin regulation in a mouse model of depression and antidepressant action. Nat Neurosci 9:519-525. CrossRef Medline

Wang C, Bomberg E, Levine A, Billington C, Kotz CM (2007) Brain-derived neurotrophic factor in the ventromedial nucleus of the hypothalamus reduces energy intake. Am J Physiol Regul Integr Comp Physiol 293: R1037-R1045. CrossRef Medline

Warden D, Rush AJ, Trivedi MH, Fava M, Wisniewski SR (2007) The $S_{T A R}{ }^{*} D$ Project results: a comprehensive review of findings. Curr Psychiatry Rep 9:449-459. CrossRef Medline

Wei R, Lin CM, Tu YY (2010) Strain-specific BDNF expression of rat primary astrocytes. J Neuroimmunol 220:90-98. CrossRef Medline

Wilkinson MB, Xiao G, Kumar A, LaPlant Q, Renthal W, Sikder D, Kodadek TJ, Nestler EJ (2009) Imipramine treatment and resiliency exhibit similar chromatin regulation in the mouse nucleus accumbens in depression models. J Neurosci 29:7820-7832. CrossRef Medline

Wu PJ, Chang SM, Lu MK, Chen WJ, Yang YK, Yeh TL, Liao SC, Lu RB, Kuo PH (2012) The profile and familiality of personality traits in mood disorder families. J Affect Disord 138:367-374. CrossRef Medline

Yan HC, Qu HD, Sun LR, Li SJ, Cao X, Fang YY, Jie W, Bean JC, Wu WK, Zhu XH, Gao TM (2010) Fuzi polysaccharide-1 produces antidepressantlike effects in mice. Int J Neuropsychopharmacol 13:623-633. CrossRef Medline

Zeng Y, Tan M, Kohyama J, Sneddon M, Watson JB, Sun YE, Xie CW (2011) Epigenetic enhancement of BDNF signaling rescues synaptic plasticity in aging. J Neurosci 31:17800-17810. CrossRef Medline

Zhang K, Siino JS, Jones PR, Yau PM, Bradbury EM (2004) A mass spectrometric "Western blot" to evaluate the correlations between histone methylation and histone acetylation. Proteomics 4:3765-3775. CrossRef Medline

Zhao H, Shiina H, Greene KL, Li LC, Tanaka Y, Kishi H, Igawa M, Kane CJ, Carroll P, Dahiya R (2005) CpG methylation at promoter site -140 inactivates TGFbeta2 receptor gene in prostate cancer. Cancer 104: 44-52. CrossRef Medline 